\title{
Methane cross-validation between three Fourier transform spectrometers: SCISAT ACE-FTS, GOSAT TANSO-FTS, and ground-based FTS measurements in the Canadian high Arctic
}

\author{
Gerrit Holl $^{1, \text { a }}$, Kaley A. Walker ${ }^{1}$, Stephanie Conway ${ }^{1}$, Naoko Saitoh ${ }^{2}$, Chris D. Boone ${ }^{3}$, Kimberly Strong ${ }^{1}$, and \\ James R. Drummond ${ }^{4}$ \\ ${ }^{1}$ Department of Physics, University of Toronto, Toronto, ON, Canada \\ ${ }^{2}$ Center for Environmental Remote Sensing, Chiba University, Chiba, Japan \\ ${ }^{3}$ Department of Chemistry, University of Waterloo, Waterloo, ON, Canada \\ ${ }^{4}$ Department of Physics and Atmospheric Science, Dalhousie University, \\ Halifax, NS, Canada \\ ${ }^{a}$ now at: Department of Meteorology, University of Reading, Reading, UK \\ Correspondence to: Kaley A. Walker (kaley.walker@utoronto.ca)
}

Received: 3 November 2015 - Published in Atmos. Meas. Tech. Discuss.: 15 December 2015

Revised: 8 March 2016 - Accepted: 10 March 2016 - Published: 3 May 2016

\begin{abstract}
We present cross-validation of remote sensing measurements of methane profiles in the Canadian high Arctic. Accurate and precise measurements of methane are essential to understand quantitatively its role in the climate system and in global change. Here, we show a crossvalidation between three data sets: two from spaceborne instruments and one from a ground-based instrument. All are Fourier transform spectrometers (FTSs). We consider the Canadian SCISAT Atmospheric Chemistry Experiment (ACE)-FTS, a solar occultation infrared spectrometer operating since 2004, and the thermal infrared band of the Japanese Greenhouse Gases Observing Satellite (GOSAT) Thermal And Near infrared Sensor for carbon Observation (TANSO)-FTS, a nadir/off-nadir scanning FTS instrument operating at solar and terrestrial infrared wavelengths, since 2009. The ground-based instrument is a Bruker 125HR Fourier transform infrared (FTIR) spectrometer, measuring mid-infrared solar absorption spectra at the Polar Environment Atmospheric Research Laboratory (PEARL) Ridge Laboratory at Eureka, Nunavut $\left(80^{\circ} \mathrm{N}, 86^{\circ} \mathrm{W}\right)$ since 2006. For each pair of instruments, measurements are collocated within $500 \mathrm{~km}$ and $24 \mathrm{~h}$. An additional collocation criterion based on potential vorticity values was found not to significantly affect differences between measurements. Profiles are regridded to a common vertical grid for each
\end{abstract}

comparison set. To account for differing vertical resolutions, ACE-FTS measurements are smoothed to the resolution of either PEARL-FTS or TANSO-FTS, and PEARL-FTS measurements are smoothed to the TANSO-FTS resolution. Differences for each pair are examined in terms of profile and partial columns. During the period considered, the number of collocations for each pair is large enough to obtain a good sample size (from several hundred to tens of thousands depending on pair and configuration). Considering full profiles, the degrees of freedom for signal (DOFS) are between 0.2 and 0.7 for TANSO-FTS and between 1.5 and 3 for PEARL-FTS, while ACE-FTS has considerably more information (roughly 1 DOFS per altitude level). We take partial columns between roughly 5 and $30 \mathrm{~km}$ for the ACE-FTS-PEARL-FTS comparison, and between 5 and $10 \mathrm{~km}$ for the other pairs. The DOFS for the partial columns are between 1.2 and 2 for PEARL-FTS collocated with ACE-FTS, between 0.1 and 0.5 for PEARL-FTS collocated with TANSO-FTS or for TANSO-FTS collocated with either other instrument, while ACE-FTS has much higher information content. For all pairs, the partial column differences are within $\pm 3 \times 10^{22}$ molecules $\mathrm{cm}^{-2}$. Expressed as median \pm median absolute deviation (expressed in partial column units or as a percentage), these differences are $0.11 \pm 9.60 \times 10^{20}$ molecules $\mathrm{cm}^{-2}$ 
$(0.012 \pm 1.018 \%)$ for TANSO-FTS-PEARL-FTS, $-2.6 \pm 2.6 \times 10^{21}$ molecules $\mathrm{cm}^{-2}(-1.6 \pm 1.6 \%)$ for ACEFTS-PEARL-FTS, and $7.4 \pm 6.0 \times 10^{20}$ molecules $\mathrm{cm}^{-2}$ $(0.78 \pm 0.64 \%)$ for TANSO-FTS-ACE-FTS. The differences for ACE-FTS-PEARL-FTS and TANSO-FTS-PEARL-FTS partial columns decrease significantly as a function of PEARL partial columns, whereas the range of partial column values for TANSO-FTS-ACE-FTS collocations is too small to draw any conclusion on its dependence on ACE-FTS partial columns.

\section{Introduction}

Methane is the third largest contributing greenhouse gas in the Earth atmosphere, after water vapour and carbon dioxide (Ciais et al., 2013). A quantitative understanding of the methane cycle is needed to model present and future climate. Accurate measurements are needed to constrain long-term sources and sinks (Ciais et al., 2013).

Methane has both natural and anthropogenic sources, and has an atmospheric lifetime of approximately 9 years (Prather et al., 2012). Anthropogenic sources, such as livestock, landfills, and fossil fuels, account for approximately $352 \pm 45 \mathrm{Tg} \mathrm{yr}^{-1}$, whereas natural sources total $202 \pm$ $35 \mathrm{Tg} \mathrm{yr}^{-1}$ (Prather et al., 2012). Total methane concentrations are estimated to have risen from $700 \pm 25$ ppbv in preindustrial times to $1795 \pm 18$ ppbv in 2010 (Prather et al., 2012). The largest natural source of methane is from wetlands, which are concentrated at high northern latitudes (50$75^{\circ} \mathrm{N}$ ) (Melton et al., 2013). Models disagree about the trend and feedbacks for wetland methane emissions (e.g. Ciais et al., 2013; Melton et al., 2013). The northern latitudes where wetlands dominate are poorly sampled by groundbased measurement networks (either in situ or remote sensing). Therefore, only spaceborne remote sensing can deliver the spatial and temporal coverage needed to constrain models. Due to the difficult nature of satellite remote sensing in an area where solar elevation angles are low and surfaces are cold and snow-covered, targeted validation of spaceborne methane measurements in the Arctic is needed.

Satellite validation is the process of verifying that remotely sensed geophysical products (such as methane concentrations) are consistent with a reference "ground" truth while taking into account accuracy, known biases, and precision (von Clarmann, 2006). Validation is carried out by performing a comparison against a reference that can be considered as a truth, or that is itself validated. Often, when such a truth is not available, an alternative is cross-validation. A cross-validation seeks to verify that measurements reported by a set of products are mutually consistent within reported error ranges (von Clarmann, 2006).

Previous studies have validated spaceborne methane measurements in different contexts. A brief overview of the his- tory of spaceborne methane measurements is included in the broad review by Thies and Bendix (2011), with considerably more detail in the slightly older review by Bréon and Ciais (2010). Spaceborne methane measurements use different techniques. Down-looking (nadir or slant) shortwave measurements (i.e. from reflected solar radiation), such as from the SCanning Imaging Absorption SpectroMeter for Atmospheric CHartographY (SCIAMACHY) (Frankenberg et al., 2005), or the Greenhouse Gases Observing Satellite (GOSAT) Thermal And Near infrared Sensor for carbon Observation (TANSO)-Fourier transform spectrometer (FTS) shortwave (Yoshida et al., 2011; Morino et al., 2011; Inoue et al., 2014), are limited to total columns in daytime clear-sky conditions. Thermal infrared measurements, such as from the Tropospheric Emission Spectrometer (TES) (Worden et al., 2012; Wecht et al., 2012), the Atmospheric InfraRed Sounder (AIRS) (Xiong et al., 2008), the Infrared Atmospheric Sounding Interferometer (IASI) (Razavi et al., 2009), or the GOSAT TANSO-FTS Thermal Infra-Red (TIR) band (Saitoh et al., 2012) do not depend on the Sun and have the potential to measure the vertical distribution, although the latter depends on the spectral ranges used and on sufficient degrees of freedom for signal (DOFS) being available in the measurement (at least 2 DOFS are needed to resolve vertical information). Even where the measurement contains insufficient information for resolving features vertically, thermal infrared can still complement shortwave observations whose sensitivity generally maximizes lower in the troposphere, and thus (in the case of methane) closer to the sources. Measurements in a limb geometry, such as from the Michelson Interferometer for Passive Atmospheric Sounding (MIPAS) (Raspollini et al., 2006), have a higher vertical resolution but a less precise horizontal geolocation due to the long path through the atmosphere, and cannot measure close to the surface. One type of limb measurements are solar occultation measurements, such as those carried out by the Atmospheric Chemistry Experiment (ACE)-FTS (De Mazière et al., 2008). Looking at a solar source, those measurements have a very high signal to noise ratio, at the price of a low number of measurements (two profiles measured per orbit).

The aim of this study is to cross-validate methane profile products near Eureka, Nunavut, Canada $\left(80^{\circ} \mathrm{N}, 86^{\circ} \mathrm{W}\right)$. We consider one spaceborne occultation instrument (ACE-FTS), one spaceborne nadir/off-nadir instrument (TANSO-FTS, the TIR band), and one ground-based solar absorption instrument, all described in Sect. 2.1. We compare each pair of products in a round-robin sense (each instrument is compared against all others), to verify that the differences are consistent with expected bias, accuracy, and precision.

The paper is set up as follows. Section 2 describes in detail the instruments involved and the cross-validation methodology implemented. Section 3 presents results on the vertical resolution of the different instruments involved, as well as comparisons of profiles and partial columns. In Sect. 4, those results are interpreted and put in a wider context. Finally, 
Sect. 5 contains conclusions and recommendations for future work.

\section{Methods}

\subsection{Instruments and products}

\subsubsection{PEARL-FTS}

Since 2006, a Bruker IFS 125HR has operated at the Polar Environment Atmospheric Research Laboratory (PEARL) Ridge Laboratory at $80.05^{\circ} \mathrm{N}, 86.42^{\circ} \mathrm{W}$, at an elevation of 610 ma.s.l. (Batchelor et al., 2009; Fogal et al., 2013).

As part of the Network for the Detection of Atmospheric Composition Change (NDACC) (http://www.ndsc. ncep.noaa.gov/) the Fourier transform infrared (FTIR) makes measurements using seven narrow-band filters covering the range between 670 and $4300 \mathrm{~cm}^{-1}(14.9$ and $2.33 \mu \mathrm{m})$ with a spectral resolution of $0.004 \mathrm{~cm}^{-1}$. Methane retrievals are based on an optimal estimation method in the framework of Rodgers (2000), carried out with the new SFIT4 retrieval code (https://wiki.ucar.edu/display/sfit4/Infrared+Working+ Group+Retrieval+Code,+SFIT). The retrieval iteratively improves the a priori Volume Mixing Ratio (VMR) profiles which are based on the mean of a 40 year run (1980-2020) from the Whole Atmosphere Chemistry Climate Model (WACCM) (Eyring et al., 2007; Marsh et al., 2013), version 6 , for Eureka. The retrieval strategy is based on the approach presented in Sussmann et al. (2011). The retrieval process outputs methane profiles, averaging kernels, Jacobians for both the retrieval and forward model parameters, profiles of interfering species, spectral fits, root-mean-square error of fit, and retrieval error estimates. Retrievals are performed on a fixed altitude grid with 47 levels covering $91 \mathrm{kPa}-8 \mathrm{mPa}$. Pressure and temperature at altitudes below $10 \mathrm{~Pa}$ are obtained from daily National Centers for Environmental Prediction (NCEP) profiles (covering $10^{5}-10 \mathrm{~Pa}$ ), which are calculated for each NDACC site and available at ftp://ftp.cpc. ncep.noaa.gov/ndacc/ncep/. At altitudes above $10 \mathrm{~Pa}$, NCEP profiles are not available, and we use the mean temperature and pressure profiles of the aforementioned WACCM model run. Spectroscopic data are obtained from the HITRAN 2008 edition (Rothman et al., 2009).

Estimates of the measurement uncertainties are based on the formulation presented in Rodgers (1990, 2000). Uncertainties due to measurement noise and forward model parameters are calculated for each measurement. Interference errors (Rodgers and Connor, 2003) account for wavelength shift, background slope, simple retrieved phase correction and the profiles of $\mathrm{CO}_{2}, \mathrm{HDO}, \mathrm{NO}_{2}$, and $\mathrm{H}_{2} \mathrm{O}$. The forward model parameter errors considered are solar zenith angle uncertainties, temperature uncertainties and spectroscopic parameter uncertainties. Smoothing error is not included (von Clarmann, 2014).

\subsubsection{ACE-FTS}

ACE (on-board the SCISAT satellite) includes an FTS (henceforth ACE-FTS) operating at $750-4400 \mathrm{~cm}^{-1}(13.3-$ $2.27 \mu \mathrm{m}$ ) with a spectral resolution of $0.02 \mathrm{~cm}^{-1}$ (Bernath et al., 2005). It was launched on 12 August 2003, into a circular orbit with an altitude of $650 \mathrm{~km}$ and an inclination of $74^{\circ}$.

ACE-FTS is a Michelson interferometer of custom design built by ABB Inc. (Bernath et al., 2005). From two solar occultation measurements per orbit, profiles of trace gases are retrieved. The instrument has a vertical resolution of around $4 \mathrm{~km}$, measuring from the cloud tops up to $150 \mathrm{~km}$. As the current study focuses on methane, we are primarily interested in the troposphere and lower stratosphere because this is where the bulk of the methane is located and these atmospheric regions are the primary contributors to the greenhouse effect. Retrievals are performed on either a variable or a fixed altitude grid. Here, we use the retrievals on the fixed $1 \mathrm{~km}$ altitude grid (oversampled relative to the vertical resolution). Pressure and temperature are available as retrieved parameters. Spectroscopic line lists for methane are from HITRAN 2004 (Rothman et al., 2005).

We use methane profile retrievals from release V3.5. Boone et al. (2005) describe the overall retrieval strategy for ACE-FTS retrievals. Since then, the algorithm has been updated several times, with V3.0 described by Boone et al. (2013). The latest version at the time of writing is V3.5, which corrects erroneous reanalysis data used in the processing for V3.0 after September 2010.

As part of a larger validation exercise, De Mazière et al. (2008) describe validations for ACE-FTS methane profiles from V2.2, which is the version immediately preceding V3.0. Differences between V2.2 and V3.0 are described by Waymark et al. (2013). De Mazière et al. (2008) compare retrieved profiles to various other sources: 11 ground-based FTIR sites covering a range of climate zones from Arctic to Antarctic (but not Eureka), balloon-borne measurements from Spectroscopie Infra-Rouge d'Absorption par Lasers Embarqués (SPIRALE), and spaceborne measurements from MIPAS and the Halogen Occultation Experiment (HALOE). In the high-latitude Upper Troposphere-Lower Stratosphere (UTLS) region, they find ACE-FTS to be biased low to MIPAS (by around $0.1 \mathrm{ppmv}$ ), but high to SPIRALE (less than $10 \%$; HALOE has no coverage north of $57^{\circ}$ ).

Recently, Sheese et al. (2015) have empirically processed ACE-FTS measurements to detect unphysical retrieved values. They divide values in bins depending on latitude, local time, season, and altitude level. Within each bin, they fit a superposition of three Gaussian distributions, assuming the distribution is at most trimodal. Using these distributions, they then flag any retrievals determined to be an outlier with a confidence of $97.5 \%$ or larger. In our study, we have used version 1.1 of these flags to reject unphysical retrievals from further processing. 


\subsubsection{GOSAT TANSO-FTS TIR}

GOSAT carries the TANSO-FTS (Kuze et al., 2009). It was launched in January 2009 in a near-circular, sun-synchronous orbit with an inclination of $98^{\circ}$, a nominal altitude of $666 \mathrm{~km}$, and a local time ascending node of 13:00. TANSO-FTS scans $\pm 35^{\circ}$ from nadir, with a footprint at nadir of $10.5 \mathrm{~km}$. The instrument measures radiation in four spectral bands. Bands 1-3 measure reflected solar radiation, and band 4 measures infrared radiation emitted by the Earth and its atmosphere.

Total column methane is retrieved from shortwave radiances (Yoshida et al., 2011) and validated by Morino et al. (2011), who find it has a $1.2 \pm 1.1 \%$ low bias compared to the Total Carbon Column Observing Network (TCCON). In this study, we focus on the methane profiles retrieved from the thermal infrared (band $4,5.5-14.3 \mu \mathrm{m}$ or $700-1818 \mathrm{~cm}^{-1}$ ) (Saitoh et al., 2009, 2012), V1.0x. In the remainder of this article, TANSO-FTS refers to the TIR band only, unless otherwise stated.

Processing of level-1 data is described by Kuze et al. (2012). TIR-retrieved temperature and water vapour validation is described by Ohyama et al. (2013). This is the first study to validate V1.0x-retrieved methane profiles and partial columns focusing on the northern high latitudes.

V1.0x methane profiles are retrieved on fixed vertical grid levels, converted to variable pressure levels depending on the ambient temperature profile, with pressure levels ranging from $94 \mathrm{kPa}$ to $56 \mathrm{~Pa}$. Temperature and water vapour a priori profiles are obtained from Japanese Meteorological Agency Grid Point Value data (Maksyutov et al., 2008), and methane a priori profiles are obtained from a National Institute for Environmental Studies (NIES) transport model (Maksyutov et al., 2008; Saeki et al., 2013). Spectroscopic data are obtained from the HITRAN 2004 edition (Rothman et al., 2005).

According to thermal vacuum tests of TANSO-FTS before launch, the signal-to-noise ratio (SNR) was as low as approximately 70 at around the $7.8 \mu \mathrm{m} \mathrm{CH} 4$ absorption band, resulting in low information content.

\subsubsection{Derived meteorological products}

In processing collocations between PEARL-FTS and ACEFTS, we obtain scaled potential vorticity (sPV) estimates from Derived Meteorological Products (DMPs) (Manney et al., 2007). Manney et al. (2007) calculate sPV based on Potential Vorticity (PV) fields from the Goddard Earth Observing System (GEOS)-5.0 reanalysis (Rienecker et al., 2008), by applying a height-dependent scaling vector so that profiles have a similar range of values throughout the stratosphere. Then, they interpolate sPV values in space and time, to get an estimate at the location and time corresponding to an instrument measurement. For details, see Manney et al. (2007).

sPV profiles are reported along a slant path. For ACEFTS, sPV values for each altitude correspond to the location of each tangent point for the occultation measurement. For PEARL-FTS, sPV values are calculated for altitudes along the line of sight. Details on why and how we use SPV values are described in Sect. 2.5.

\subsection{Collocations}

Collocations are occasions where different pairs of instruments observe approximately the same air mass at approximately the same time (e.g. Holl et al., 2010). We calculate collocations between each pair of instruments; i.e. three sets in total: PEARL-FTS-ACE-FTS, PEARL-FTSTANSO-FTS, and ACE-FTS-TANSO-FTS. A suitable collocation time and distance (for a level 2 product) depends on the quantity of interest. As methane is relatively well-mixed and has a lifetime on the order of 9 years (Prather et al., 2012), a maximum distance of $500 \mathrm{~km}$ and a maximum time interval of $24 \mathrm{~h}$ was selected. This is similar to what previous studies have used. For example, De Mazière et al. (2008) use $500 \mathrm{~km}$ and $12 \mathrm{~h}$ for their polar comparisons, and Wecht et al. (2012) use $750 \mathrm{~km}$ and $24 \mathrm{~h}$.

In the collocation determination, we consider each profile as a point measurement, even if the profile is not vertical. For TANSO-FTS, this is the location where the line of sight intersects with the surface of the Earth. For ACE-FTS, we use the location of the $30 \mathrm{~km}$ tangent point. For PEARL-FTS, this is the location of the Ridge Laboratory. In the latter two cases, measurements are not actually occurring at those locations, but rather along a slant path with a large horizontal extent. For example, a limb sounding with a tangent altitude of $10 \mathrm{~km}$ has a $715 \mathrm{~km}$ path at altitudes between 10 and $50 \mathrm{~km}$ (as a simplified geometrical calculation shows), with a similar order of magnitude for high PEARL-FTS solar zenith angles. In Sect. 2.5 we will discuss what this implies for the present study.

Collocations between ACE-FTS and TANSO-FTS are limited to the quadrangle $60-90^{\circ} \mathrm{N}, 120-40^{\circ} \mathrm{W}$, as to remain in roughly the same geographical area as the collocations with PEARL-FTS. The larger area compared to the area immediately around PEARL allows for more collocations and therefore more complete statistics.

A single retrieval from one instrument may collocate with more than one retrieval from the other. In Sect. 2.6, we describe how this is taken into consideration.

\subsection{Vertical regridding}

Different measurements are reported on different vertical grids, as described above in Sect. 2. Therefore, we need to calculate interpolated profiles before we can perform subsequent processing steps.

To calculate altitude from pressure for TANSO-FTS, temperature and water vapour fields are regridded onto the retrieval pressure grid using a b-spline method (Dierckx, 1995). This may introduce some error above $1 \mathrm{kPa}$. However, 
as this is at altitudes above the sensitivity range of the retrieval, this does not affect subsequent processing. Pressure is converted to altitude based on the assumption of hydrostatic equilibrium.

For each collocation pair, we choose a shared altitude grid to which we interpolate profiles of retrieved methane, a priori methane, averaging kernels, temperature, and water vapour. For the new altitude grid $z_{\mathrm{n}}$, we (arbitrarily) choose the arithmetic mean altitude per level for the lower-resolution data set (i.e. we take all altitude profiles, then calculate the average $h_{i}$ for $i=1 \ldots N$ if each profile has $N$ levels). That means we have one altitude grid for each of our three comparison pairs. In regridding, we are careful not to extrapolate any profiles; any levels outside of the range of the chosen grid are flagged and not considered in subsequent processing. For the lower-resolution instrument, averaging kernels are regridded following Calisesi et al. (2005),

$\mathbf{A}_{z_{\mathrm{n}}} \approx \mathbf{W A}_{z_{\mathrm{o}}} \mathbf{W}^{*}$,

where $\mathbf{A}$ is the averaging kernel matrix, $z_{\mathrm{n}}$ is the new altitude grid, $z_{\mathrm{o}}$ is the old altitude grid, $\mathbf{W}$ is the interpolation matrix between the two grids, and ${ }^{*}$ indicates the MoorePenrose pseudo-inverse (Moore, 1920). Regridding is performed by linear interpolation, and $\mathbf{W}$ is calculated by obtaining the standard matrix of the linear transformation (Lay, 2003, p. 83),

$\mathbf{W}=\left(T\left(\boldsymbol{e}_{1}\right) \ldots T\left(\boldsymbol{e}_{n}\right)\right)$,

where $T$ can be any linear vector-valued function (in this case: linear interpolation), and $\boldsymbol{e}_{k}(k=1 \ldots n)$ is column $k$ of the identity matrix $\mathbf{I}$.

\subsection{Vertical smoothing}

We investigate the information content for each of our data sets by calculating a histogram of the DOFS for the retrievals, defined as the trace of the averaging kernel matrix A (we calculate this before the regridding described above). For each pair of collocations, one measurement has a higher vertical resolution than the other. Henceforth, we will refer to the "higher-resolution" and "lower-resolution" measurements, by which we mean vertical resolution. The higherresolution measurement is smoothed using the averaging kernel and a priori from the lower-resolution measurement, following Rodgers and Connor (2003),

$\hat{\boldsymbol{x}}_{\mathrm{s}}=\boldsymbol{x}_{\mathrm{a}}+\mathbf{A}\left(\hat{\boldsymbol{x}}_{\mathrm{h}}-\boldsymbol{x}_{\mathrm{a}}\right)$,

where $\hat{\boldsymbol{x}}_{\mathrm{h}}$ is the original higher-resolution profile, $\mathbf{A}$ and $\boldsymbol{x}_{\mathrm{a}}$ are the averaging kernel matrix and the a priori profile for the lower-resolution profile, respectively, and $\hat{\boldsymbol{x}}_{\mathrm{s}}$ is the smoothed higher-resolution profile, to be compared against the lowerresolution profile. In cases where $\hat{\boldsymbol{x}}_{\mathrm{h}}$ does not cover the full range of $\boldsymbol{x}_{\mathrm{a}}, \hat{\boldsymbol{x}}_{\mathrm{h}}$ is extended using $\boldsymbol{x}_{\mathrm{a}}$ on both sides, prior to the application of Eq. (3) because it follows from Eq. (3) that $\hat{\boldsymbol{x}}_{\mathrm{s}}=\boldsymbol{x}_{\mathrm{a}}$, where rows of $\mathbf{A}$ are $\boldsymbol{0}$.

\subsection{Natural variability and coincidence error}

Depending on the geophysical quantity of interest, it may or may not be necessary to consider natural variability. For example, von Clarmann (2006) considers that one needs to evaluate the coincidence error. He proposes to estimate this by calculating the expected natural variability based on collocation distance and time interval, using an independent source, such as from reanalysis model output. Instead, we choose to investigate whether this is needed for our methane intercomparison, by considering the effect of our collocation criteria (time and distance) on the comparison results. If reducing the collocation time and distance has no large effect on the difference, an explicit consideration of natural variability is not necessary.

None of the measurements are point measurements, but all measure along a path through the atmosphere, as described above. Due to these considerations, the parts of the atmosphere sampled by TANSO-FTS, PEARL-FTS, and ACEFTS are different, even when the nominal location is the same. This contributes to the coincidence error described above, but the same reasoning applies. A coincidence error should be expected to increase when the distance or time increases, and decrease when those decrease, ultimately disappearing in the theoretical case where two instruments sample exactly the same atmosphere at the same time. Therefore, where reducing the collocation distance criterion only has a small impact on estimated differences between instruments, the coincidence error is not of major importance, and there is no need to explicitly take the path through the atmosphere into account.

The presence of the Arctic polar vortex means that even proximate stratospheric air parcels may sample considerably different conditions (Schoeberl et al., 1992). Therefore, for the comparison between ACE-FTS and PEARL-FTS, we investigate the effect of further constraining the collocations by an SPV criterion. This is not needed for comparisons involving TANSO-FTS because it is sensitive only to the troposphere. As we choose a single level for investigating the sPV criterion (potential temperature of $700 \mathrm{~K}$ ), we do not perform any interpolation, except when comparing SPV values between two instruments. The source of our SPV values is described in Sect. 2.1.4.

\subsection{Averaging measurements}

As mentioned in Sect. 2.2, usually the same profile from one instrument collocates with more than one profile from another. For example, we have a subset of $n$ collocated pairs PEARL-FTS vs. TANSO-FTS that all correspond to one unique PEARL-FTS profile with $n$ different TANSOFTS profiles. Similar to De Mazière et al. (2008), we calculate the arithmetic mean methane profile of all TANSOFTS profiles corresponding to the same PEARL-FTS profile. Note that since we have already performed smooth- 
ing on each PEARL-FTS profile individually, by applying Eq. (3) using different TANSO-FTS averaging kernels, the set of smoothed PEARL-FTS profiles corresponding to a single original PEARL-FTS profiles now varies. Therefore, we calculate the arithmetic mean profile for both sets of profiles corresponding to a unique original PEARL-FTS profile. Note that the same TANSO-FTS profile can also collocate to more than one PEARL-FTS profile; i.e. the set of TANSO-FTS profiles collocating with PEARL-FTS profile $k$ has some overlap with the set of TANSO-FTS profiles collocating with PEARL-FTS profile $k+1$. We do no further processing to account for this.

We perform a similar operation where multiple TANSOFTS profiles correspond to the same ACE-FTS profile, or where multiple PEARL-FTS profiles correspond to the same ACE-FTS profile.

\subsection{Partial columns}

Considering the limited vertical information content for PEARL-FTS and TANSO-FTS, we compare partial column values. Each of the retrievals reports VMR. As a first step in calculating partial columns, we convert volume mixing ratio, $x$, to number density, $N$, according to the ideal gas law (Clapeyron, 1834),

$$
\frac{N}{x}=\frac{p}{k T}
$$

where $x$ is the VMR, $p$ atmospheric pressure, $T$ temperature, and $k=1.380653 \times 10^{-23} \mathrm{JK}^{-1}$ is Boltzmann's constant (Mohr et al., 2012). To convert $x$ to $N$ for both instruments, there are three reasonable alternatives for temperature and pressure: one can choose one instrument and use its pressure and temperature for both, one can convert $x$ to $N$ for each instrument using its own pressure and temperature, or one can calculate $N$ using the mean temperature and pressure between the two instruments (arithmetic mean temperature and geometric mean pressure), resulting in $N_{\text {mean }}$. None of those alternatives is perfect and each has some advantages or disadvantages. We choose to use $N_{\text {mean }}$ for use in further processing, so that temperature and pressure are consistent within the comparison ensemble. The uncertainty due to the differences in pressure and temperature is then given by

$\sigma_{p T}=\left|\frac{N_{\mathrm{sec}}-N_{\mathrm{prim}}}{2}\right|$,

where $N_{\text {prim }}$ and $N_{\text {sec }}$ are the primary and secondary number densities corresponding to the primary and secondary instrument within each collocation pair. For the temperature, we calculate the arithmetic mean. For the pressure, we calculate the geometric mean because pressure is very far from normally distributed and closer to a log-normal distribution.

To calculate partial columns from number density profiles, we need to determine an appropriate altitude range for the partial columns. ACE-FTS measurements have a high sensitivity throughout the vertical range, but PEARL-FTS and TANSO-FTS sensitivities vary as a function of altitude. For each profile, we calculate as a function of altitude the sensitivity of the retrieval to the measurement, by summing the rows of the averaging kernel (Vigouroux et al., 2007). This value, normally between 0 and 1 , indicates what fraction of the retrieved value is due to the measurement (as opposed to the a priori). From this, we calculate the altitude range $\left(h_{l}, h_{u}\right)$ where at least a fraction $f$ of the profiles have a measurement sensitivity larger than $c$. The choice of $f$ and $c$ is an optimization problem. If they are too large, the altitude range becomes very small and the result is closer to a single layer retrieval than to a partial column; but if they are too small, then a large part of the partial columns is due to the a priori and we are not really comparing measurements. There is no single obvious solution to this optimization. Specific criteria for choosing $f$ and $c$ will be presented in Sect. 3.2. Typically, it is desirable to have $c=1$ and $f=0.5$, such that half the profiles have full sensitivity at a particular altitude.

Once the altitude range is chosen, we define an operator $g$ such that levels within the range have value 1, and levels outside it have value 0 , and calculate the partial columns by

$n_{\mathrm{pc}}=\boldsymbol{g} \frac{N}{x} \hat{\boldsymbol{x}}$,

where $n_{\mathrm{pc}}$ is the partial column estimate, $\boldsymbol{g}$ is the partial column operator (i.e. a vector consisting of ones at levels within the partial column range, and 0 elsewhere), and $\hat{\boldsymbol{x}}$ is the (smoothed) methane profile. We calculate the difference in partial columns by

$\delta_{\mathrm{pc}}=n_{\mathrm{pc}, 2}-n_{\mathrm{pc}, 1}$,

where $n_{\mathrm{pc}, 2}$ and $n_{\mathrm{pc}, 1}$ are the partial column values for TANSO-FTS, ACE-FTS, and PEARL-FTS, depending on the specific comparison set.

Next, we investigate whether the partial column difference is itself a function of partial column, by fitting a first order polynomial $(y=a x+b)$ to $\delta_{\mathrm{pc}}\left(x_{\mathrm{pc}, 1}\right)$, using ordinary least squares, and we calculate the $95 \%$ confidence band around the predicted regression line. Finally, we calculate the DOFS of the newly calculated partial columns, by taking the trace of the sub-matrix of the averaging kernel, corresponding to the levels used for partial column calculations.

\subsection{Error analysis}

In order to address the core question of a cross-validation study - are the retrievals consistent? - it is critically important to address error estimates. If we assume that the higherresolution measurement has a much higher resolution than the lower-resolution measurement, a simplification of Calisesi et al. (2005, Eq. 22) gives

$\mathbf{S}_{\delta_{12}}=\mathbf{S}_{1}+\mathbf{A}_{1} \mathbf{W}_{12} \mathbf{S}_{2} \mathbf{W}_{12}{ }^{\mathrm{T}} \mathbf{A}_{1}^{\mathrm{T}}$, 
which is identical to the result found by Vigouroux et al. (2007). Here, $\mathbf{S}$ is the random error covariance matrix, $\mathbf{A}$ is the averaging kernel matrix, the subscript ${ }_{1}$ relates to the lower-resolution retrieval, and the subscript 2 relates to the higher-resolution retrieval. $\mathbf{W}_{12}$ is the grid transformation matrix calculated by $\mathbf{W}_{12}=\mathbf{W}_{1}^{*} \mathbf{W}_{2}$ (Calisesi et al., 2005), and ${ }^{*}$ indicates again the Moore-Penrose pseudo-inverse (see also Eq. 2).

To calculate the variance in the partial column, we use

$\sigma_{\mathrm{PC}}=\boldsymbol{g} \mathbf{S}_{\delta_{12}} \boldsymbol{g}^{\mathrm{T}}$,

where the calculation of $\boldsymbol{g}$ is described in Sect. 2.7.

PEARL-FTS provides the random error covariance matrix directly for all retrievals, but ACE-FTS and TANSOFTS do not. As ACE-FTS is a limb observing instrument, the information content can be approximated by one degree of freedom per retrieval level. Consequently, the error covariance between different retrieval levels for ACE-FTS is far lower than for the other retrievals considered in this study. Therefore, we neglect those covariances and approximate $\mathbf{S}_{\mathrm{ACE}-\mathrm{FTS}}$ as a diagonal matrix, with $\mathbf{S}_{\mathrm{ACE}-\mathrm{FTS}, i, i}=\sigma_{i}^{2}$ and $\mathbf{S}_{\mathrm{ACE}-\mathrm{FTS}, i, j}=0$ where $i \neq j$.

For TANSO-FTS retrievals, error covariances were calculated only for a limited number of TANSO-FTS retrievals for computational reasons. For each of the TANSO-FTS profiles where we have not calculated the covariance matrix, we need to choose a representative covariance matrix corresponding to a profile for which one is available. To calculate which profile to choose, we divide the TANSO-FTS profiles into bins according to their latitude, longitude, DOFS, retrieved partial column methane (see Sect. 2.7), time of year, and local time. Specifically, we used 12 bins for day of year, 5 bins for mean local solar time, 5 for latitude, 5 for longitude, 10 for partial column methane, and 10 for DOFS, where the bins are spanned linearly between the extreme values in the collocation database. Although this gives a theoretical number of $12 \times 5 \times 5 \times 5 \times 10 \times 10=150000$ bins, only $n \ll 150000$ of those contain a non-zero number of profiles. For each of those $n$ bins, we select one profile at random, according to a uniform distribution. For the selected profile, we calculate the error covariance matrix, which we then use for all profiles within the same bin.

Secondly, as TANSO-FTS retrievals are performed in logarithmic space, TANSO-FTS error covariance matrices are in units of $\log \mathrm{ppmv}^{2}$ and cannot be directly considered in Eq. (8). To estimate $\operatorname{Cov}(\hat{\boldsymbol{x}}, \hat{\boldsymbol{x}})$ from $\operatorname{Cov}(\log (\hat{\boldsymbol{x}}), \log (\hat{\boldsymbol{x}}))$, we use the approximation

$\mathbf{S}_{\mathrm{lin}}=\operatorname{Cov}(\hat{\boldsymbol{x}}, \hat{\boldsymbol{x}}) \approx E(\hat{\boldsymbol{x}})^{2} e^{\operatorname{Cov}(\log (\hat{\boldsymbol{x}}), \log (\hat{\boldsymbol{x}}))-1}$,

where $\operatorname{Cov}(\hat{\boldsymbol{x}}, \hat{\boldsymbol{x}})$ is the covariance in linear terms, $E(\hat{\boldsymbol{x}})$ is the expectation value of $\hat{\boldsymbol{x}}$, and $\operatorname{Cov}(\log (\hat{\boldsymbol{x}}), \log (\hat{\boldsymbol{x}}))$ is the covariance in logarithmic terms. For $E(\hat{\boldsymbol{x}})$, we use the retrieved state vector $\hat{\boldsymbol{x}}$. See Appendix A for a derivation of Eq. (10).

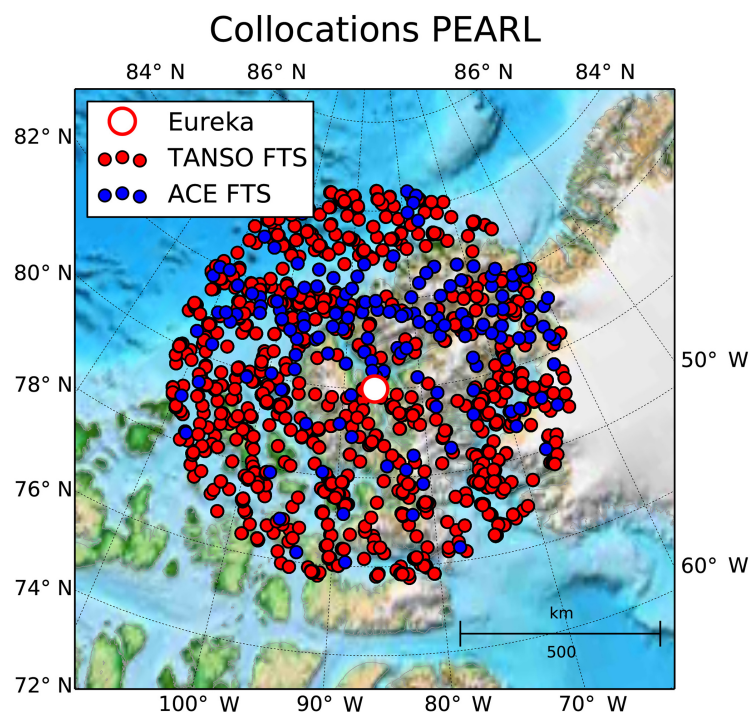

Figure 1. Geographic map showing northeastern Nunavut (Canada), northwestern Greenland, and surrounding islands, in a Lambert azimuthal equal-area projection (Lambert, 1772). The background shows bathymetry in blue tones, elevation in green and brown tones, and land ice with areas larger than $100 \mathrm{~km}^{2}$ in white, as calculated by NOAA ETOPO1 (Amante and Eakins, 2009). The white circle with a red edge in the centre of the map shows the location of the PEARL Ridge Lab near Eureka, Nunavut. The red and blue dots with black edges show the locations of TANSO-FTS and ACE-FTS profiles within $500 \mathrm{~km}$ and $24 \mathrm{~h}$ of PEARL, in the time period indicated in Table 1.

As described earlier in Sect. 2.2, not every collocation pair is unique. For example, for a single PEARL-FTS measurement, there may be several matching TANSO-FTS measurements. Taking the arithmetic mean of a set of TANSO-FTS profiles affects the effective errors. If we assume the random errors between $N$ different TANSO-FTS measurements to be uncorrelated, then the effective $\mathbf{S}_{\mathrm{eff}}=\frac{\mathbf{S}}{\sqrt{N}}$. However, we cannot say the same for the combined error $\mathbf{S}_{\delta_{12}}$, because for those $N$ pairs, each PEARL-FTS measurement is the same, so its errors are certainly not independent (their correlation is equal to 1$)$.

\section{Results and discussion}

In the following sections, we describe the results of the processing steps described above. This section is structured similarly to the previous one. First, we describe the results of collocations, vertical regridding, smoothing, and the investigation of the coincidence error. Then, we present results for the profile and partial column comparisons.

\subsection{Collocations}

Figure 1 shows a map of the collocations for the PEARLFTS-TANSO-FTS and PEARL-FTS-ACE-FTS pairs. Ta- 
Table 1. Collocation statistics for the different collocation pairs. Collocations between ACE-FTS and TANSO-FTS are limited to the quadrangle $60-90^{\circ} \mathrm{N}, 120-40^{\circ} \mathrm{W}$. The total number of collocations considers all pairs before averaging. After averaging, the number of collocations is equal to the number indicated in the row "No. primary". "Med. dist" is the median distance for all pairs. "Dist. mean" is the distance between the arithmetic mean positions (as calculated using the World Geodetic System (WGS)-84 ellipsoid) of each instrument in the pair.

\begin{tabular}{lccc}
\hline $\begin{array}{l}\text { Primary } \\
\text { Secondary }\end{array}$ & PEARL-FTS & PEARL-FTS & ACE-FTS \\
TANSO-FTS & ACE-FTS & TANSO-FTS \\
\hline First collocation & 24 February 2010 & 27 September 2006 & 2 February 2010 \\
Last collocation & 19 September 2011 & 15 March 2013 & 19 September 2011 \\
No. collocations & 20741 & 1342 & 4685 \\
No. primary & 939 & 522 & 370 \\
No. secondary & 2804 & 149 & 2916 \\
Med. dist $[\mathrm{km}]$ & 376.39 & 313.28 & 355.09 \\
Dist. mean $[\mathrm{km}]$ & 33.86 & 163.11 & 38.61 \\
\hline
\end{tabular}

ble 1 shows the number of collocations between the three data sets and the period throughout which collocations are found. The table shows both the total number of collocations, as well as the number of unique measurements for each data set. From the methodology of calculating the arithmetic mean where many profiles from one data set collocate with a single profile from the other, it follows that after this processing has been performed, the number of pairs corresponds to the table row "primary". The median distance is between 300 and $400 \mathrm{~km}$ for each pair. The distance between the arithmetic geographic mean ranges from $33.8 \mathrm{~km}$ for PEARLFTS-TANSO-FTS to $163.1 \mathrm{~km}$ for PEARL-FTS-ACE-FTS.

\subsection{Vertical resolution and information content}

Figure 2 shows the mean of the averaging kernel matrices for the entire period of collocations between PEARL-FTS and TANSO-FTS. As discussed before, the vertical resolution for ACE-FTS is much higher than for PEARL-FTS or TANSO-FTS, and we approximate ACE-FTS averaging kernels by the identity matrix. Note that regridding and smoothing as described in Sect. 2.4 is only applied where we are comparing products directly against each other (profiles or partial columns) and has not been done for results presented in this section.

Figure 3 shows a histogram of DOFS for PEARL-FTS and TANSO-FTS measurements, for all pairs where the two are collocated. The figure illustrates that whereas PEARL-FTS measurements contain mostly between 1.5 and 3 DOFS and therefore have some profile content, the same is not true for TANSO-FTS, where most profiles have less than 0.5 DOFS, with some below 0.3. Clearly, there is no profile information here. However, as the DOFS are larger than 0, there is still some information in the measurement.

Considering the variable information content for PEARLFTS and the very low information content for TANSO-FTS, we investigate how information content varies as a function of latitude, longitude, time of year, time of day, and methane partial column. It was found that for both PEARL-

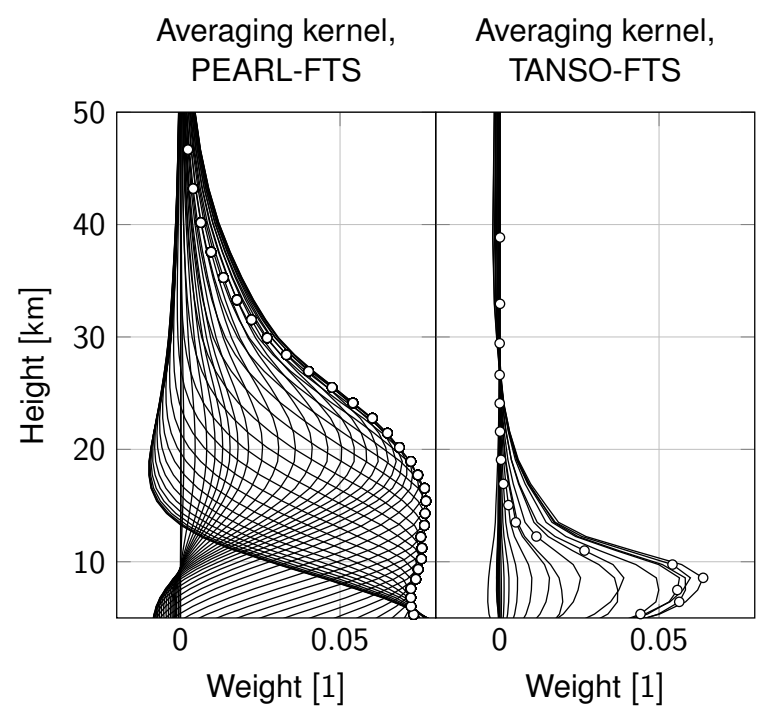

Figure 2. Arithmetic mean of all averaging kernels for the set of collocations between PEARL-FTS and TANSO-FTS. The left panel shows averaging kernels for PEARL-FTS and the right panel shows averaging kernels for TANSO-FTS. The white circles with a black edge indicate the nominal altitude for each retrieval level.

FTS and TANSO-FTS, the most dominant factor controlling the DOFS is the time of year, followed by the methane partial column.

Figure 4 shows the information content of the TANSOFTS profiles as a function of time of year and methane partial column. Note that although the figure shows information content in the entire profile, the vertical axis shows partial columns. TANSO-FTS retrievals have very low DOFS between September and May. This period corresponds to a cold and snow-covered surface in Eureka, and the very low thermal contrast complicates a retrieval from nadir/off-nadir observations in the thermal infrared at this time. In July, when the surface is warmer, the retrievals have a higher number of DOFS; in a few cases up to 0.7 or above. 


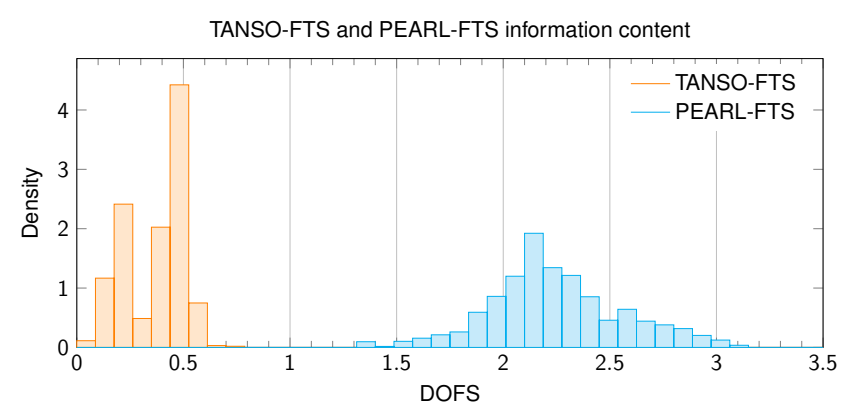

Figure 3. Histogram of the total DOFS per retrieved profile for the set of collocations between PEARL-FTS and TANSO-FTS. The histograms are normalized such that the total area for each histogram equals 1 .

A different pattern is visible for PEARL-FTS information content as shown in Fig. 5. The largest DOFS, with values up to 3, are found in late February, just after the end of the polar night, and in late September/early October, just before the beginning of the polar night. The ground-based PEARL-FTS is not negatively affected by a cold surface or snow-cover, but rather benefits from the longer optical path through the atmosphere early and late in the observing season, when the Sun is closer to the horizon. Around midsummer, the optical path is shorter, and the information content in the measurement is smaller. However, even when PEARL-FTS is at its worst and TANSO-FTS is at its best, the PEARL-FTS measurement still has more than twice the information content of the TANSO-FTS one.

Figure 6 shows the fraction of PEARL-FTS profiles at a particular altitude level that has sensitivity (defined in Sect. 2.7) larger than $c$, where $c$ varies between 0 and 1 . We can see that (almost) all profiles have sensitivity close to 1 below an altitude of approximately $25 \mathrm{~km}$, whereas a much smaller fraction of profiles has such a high sensitivity at higher altitudes. From the data used to produce Fig. 6, we select an altitude range to use for partial columns. Specifically, for a threshold where $50 \%$ of profiles have at least $50 \%$ sensitivity, we find a range of $0.9-29.9 \mathrm{~km}$ for partial columns. Note that this relates only to the profiles collocated to TANSO-FTS.

Figure 7 shows the same for TANSO-FTS profiles collocated to PEARL-FTS. In the case of TANSO-FTS, we do not have any profiles that have a sensitivity close to 1 at any altitude, and even a sensitivity of 0.5 is rarely reached. TANSOFTS sensitivity peaks in the range $7-9 \mathrm{~km}$, and in this range, at most $16 \%$ of profiles have a sensitivity of at least 0.5 . Therefore, for partial columns including TANSO-FTS, we cannot use the same criterion as for PEARL-FTS. Rather, we select the range where at least $20 \%$ of the profiles have at least $30 \%$ sensitivity, and arrive at a range of $5.2-9.5 \mathrm{~km}$ (in comparisons with PEARL-FTS, the lower limit is $5.3 \mathrm{~km}$, due to regridding and rounding).

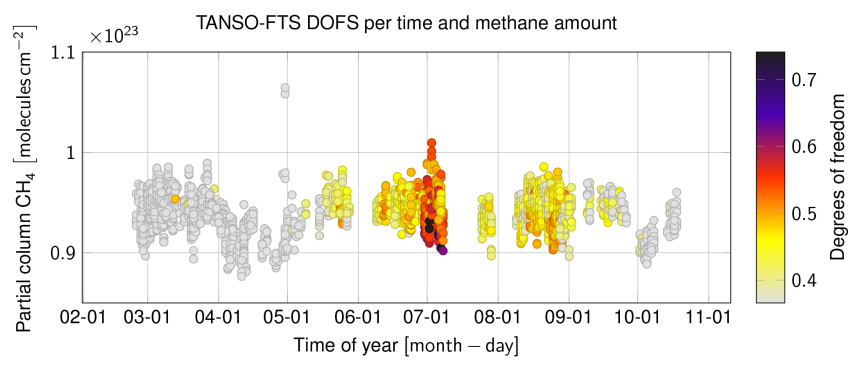

Figure 4. TANSO-FTS DOFS per profile as a function of season and methane partial column. The calculation of partial columns is described in Sect. 2.7, and the range of altitudes considered is described in Table 2. The vertical axis shows TANSO-FTS partial columns for $5.3-9.7 \mathrm{~km}$, but DOFS relate to the entire profile. The figure includes all 2804 TANSO-FTS profiles collocated with PEARL-FTS.

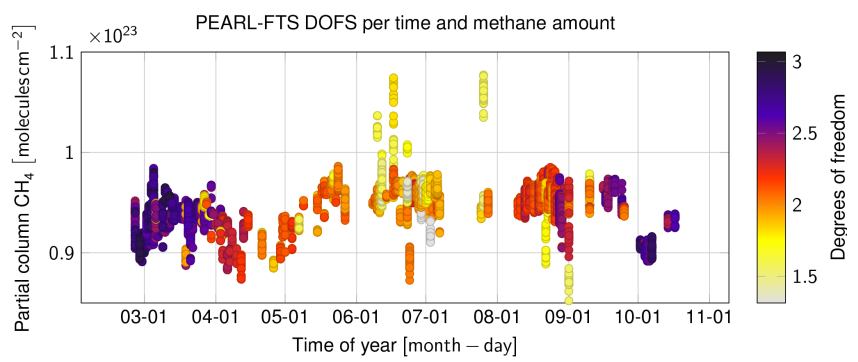

Figure 5. As in Fig. 4, but for PEARL-FTS. The vertical axis shows PEARL-FTS partial columns for $5.3-9.7 \mathrm{~km}$, but DOFS relate to the entire profile. The figure includes all 939 PEARL-FTS profiles collocated with TANSO-FTS. Note that the range of DOFS here is much larger than for Fig. 4.

\subsection{Polar vortex and coincidence error}

Figure 8 shows profiles of sPV (see Sect. 2.1.4) for the collocations between PEARL-FTS and ACE-FTS, before selecting pairs based on sPV values. The PEARL-FTS-ACEFTS comparison is the only pair that has sensitivity at stratospheric altitudes, so it is the only pair for which sPV values are relevant. The figure shows sPV profiles for all measurements in the comparison ensemble. Broadly speaking, the range of sPV values increases with increasing elevation, with values up to $2 \times 10^{-4} \mathrm{~s}^{-1}$ near the surface and up to $5 \times 10^{-4} \mathrm{~s}^{-1}$ at $50 \mathrm{~km}$. At most elevations, sPV profiles exist at any value between the extrema. However, between 17 and $32 \mathrm{~km}$, PEARL-FTS clearly shows a bimodal distribution of sPV values, which are mostly either smaller than $2 \times 10^{-4} \mathrm{~s}^{-1}$ or larger than $3 \times 10^{-4} \mathrm{~s}^{-1}$. For ACE-FTS, the sPV profiles are more noisy, and the distinction is not as clear; probably due to the fact that ACE-FTS measurements are spread over a large area, whereas PEARL-FTS measurements are all from the same location. Consequently, we do not see the same bimodal distribution in the difference panel either. 


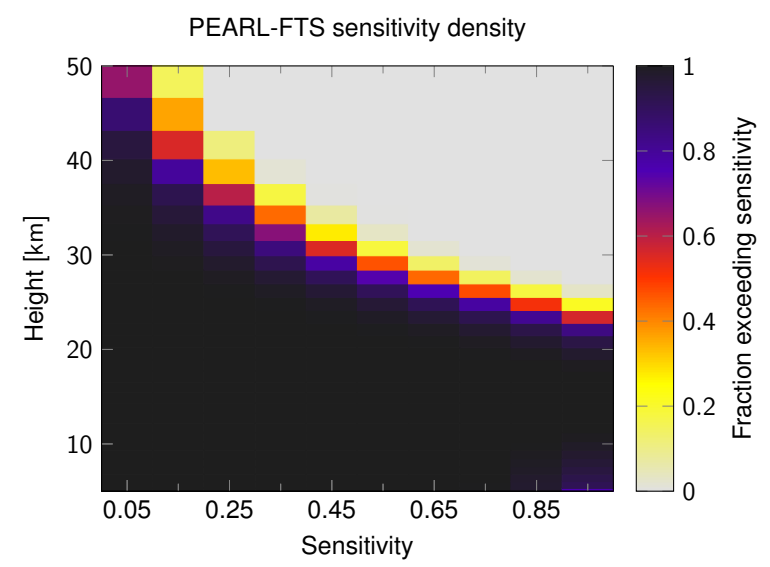

Figure 6. Sensitivity density (see Sect. 3.2) for PEARL-FTS retrievals collocated with TANSO-FTS.

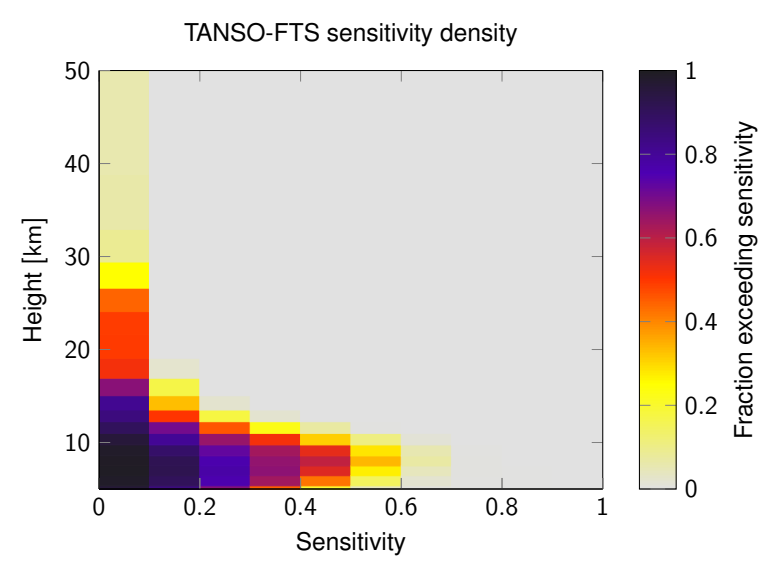

Figure 7. Sensitivity density (see Sect. 3.2) for TANSO-FTS retrievals collocated with PEARL-FTS.

\subsection{Profile comparisons}

Figure 9 shows the distribution of methane profiles for the comparison between PEARL-FTS and ACE-FTS, where the latter is either smoothed or unsmoothed (in this and subsequent figures, the unsmoothed profiles and differences are referred to as "raw"). The figure illustrates the known pattern that methane is approximately constant as a function of altitude in the troposphere, but decreases approximately linearly with altitude in the stratosphere. The raw ACE-FTS profiles show a "wiggle" at an altitude of around 20-25 km, but this disappears in the smoothed version and is not visible in the PEARL-FTS profiles (which, as shown before, have only around 2DOFS). The figure also illustrates that the distribution of methane in the stratosphere is clearly nonGaussian, as both PEARL-FTS and ACE-FTS agree that the 1st quartile is considerably further from the median than the 3 rd. This justifies our choice of median and quartiles, and implies that showing methane distributions using the mean and standard deviation may be inappropriate.
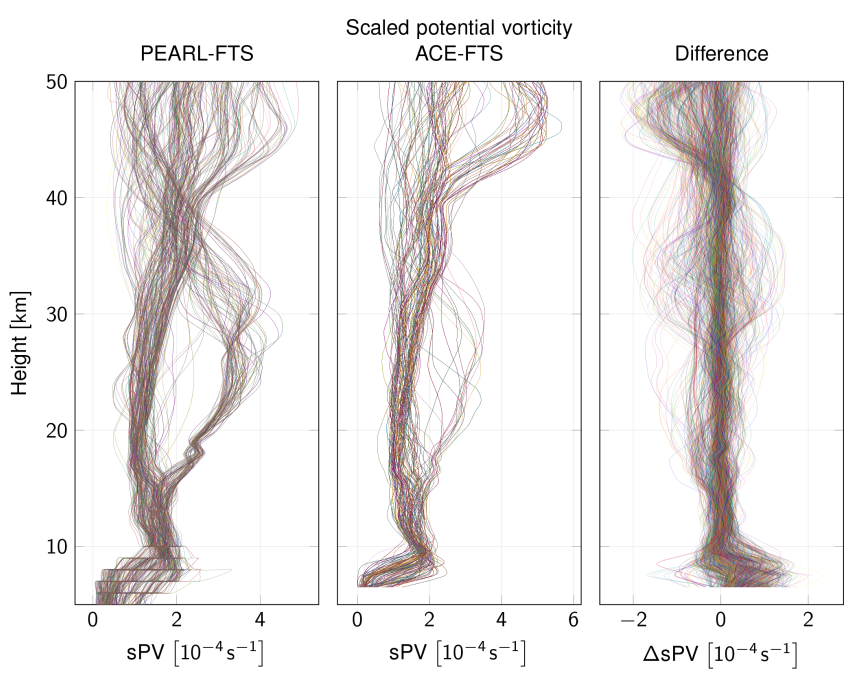

Figure 8. Profiles of sPV as a function of geometric height, for PEARL-FTS (left panel) and ACE-FTS (centre panel). The right panel shows difference profiles, i.e. $\mathrm{SPV}_{\mathrm{ACE}-\mathrm{FTS}}-\mathrm{sPV}$ PEARL-FTS For the difference figure, ACE-FTS sPV profiles were interpolated onto the vertical grid of PEARL-FTS profiles. Only collocated pairs are considered.

Figure 10 shows the distribution of differences between PEARL-FTS and ACE-FTS. In this comparison, we show an "unfiltered" version and a "filtered" version. The "unfiltered" version contains all collocated profiles, whereas the "filtered" version shows only profiles where the sPV values at the potential temperature level $700 \mathrm{~K}$ differ at most by $0.2 \times 10^{-4} \mathrm{~s}^{-1}$. The figures show that at all altitudes, smoothed ACE-FTS measurements are, on average, smaller than PEARL-FTS measurements, with the median difference ACE-FTS-PEARL-FTS between -10 and -70 ppbv. The 1st and 3rd quartile illustrate that the differences are not normally distributed, something already apparent from Fig. 9. For example, between 10 and $20 \mathrm{~km}$, the 1 st quartile of the smoothed difference clearly diverges from the median, whereas the 3rd quartile approximately follows the pattern of the median. Apart from the very lowest altitudes, near the lower boundary of the ACE-FTS measurements, the 3rd quartile of ACE-FTS-PEARL-FTS is positive with values between 10 and $50 \mathrm{ppbv}$, which means that a significant minority of pairs have the smoothed ACE-FTS measurement larger than the PEARL-FTS measurement. At altitudes above $30 \mathrm{~km}$, the absolute differences between smoothed ACE-FTS and PEARL-FTS gradually decreases, as shown by the median and the distribution. This is expected because with increasing altitude, both the methane VMR and the sensitivity of PEARL-FTS decrease. For the comparison between PEARL-FTS and unsmoothed ("raw") ACE-FTS, the median of the difference fluctuates strongly, exceeding $-100 \mathrm{ppbv}$ at an altitude of $50 \mathrm{~km}$. Differences with unsmoothed ACE-FTS that are not seen in differences with the smoothed ACE-FTS 


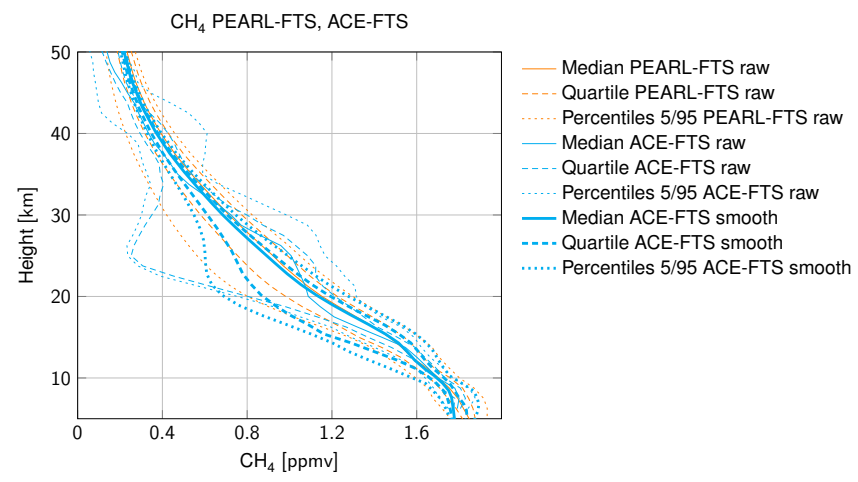

Figure 9. Distribution of retrieved methane profiles for all collocations between PEARL-FTS and ACE-FTS. In this and following figures, the solid line indicates the median value for the set of all collocated profiles as a function of altitude. The dashed line indicates the 1st and 3rd quartile (25th and 75th percentile), and the dotted line indicates the $1 \mathrm{st}$ and 99 th percentile. The set of thin lines shows the distribution of the unsmoothed profiles, labelled "raw" and interpolated on a shared altitude grid, whereas the thick lines show the smoothed profiles. The calculation method is described in the text.

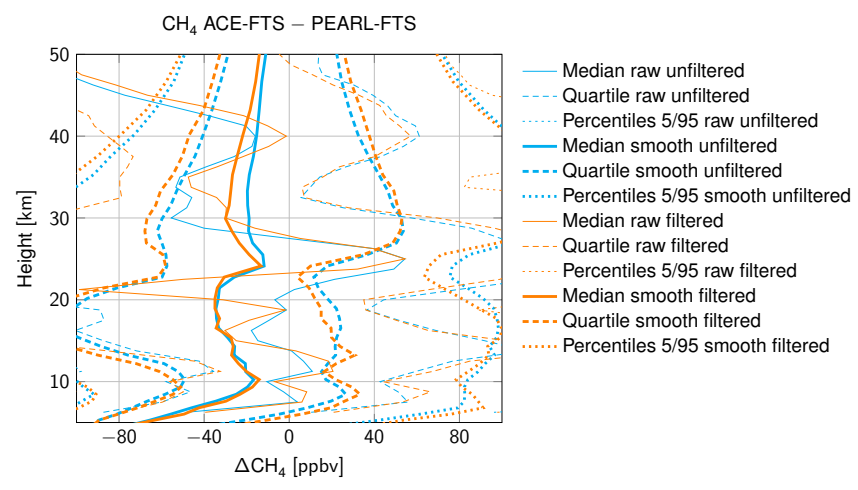

Figure 10. Distribution of the difference between profiles for ACEFTS-PEARL-FTS. Solid, dashed, and dotted lines show the distribution of the difference as a function of altitude, similar to how they show the distribution of methane in Fig. 9. The blue lines show the differences for all profiles (labelled "unfiltered"), whereas the orange lines show the differences only for those profiles where $\Delta \mathrm{sPV}_{\theta=700 \mathrm{~K}} \leq 0.2 \times 10^{-4} \mathrm{~s}^{-1}$, where $\mathrm{sPV}_{\theta=700 \mathrm{~K}}$ is the scaled potential vorticity at a height corresponding to a potential temperature $\theta$ of $700 \mathrm{~K}$ along the line of sight, labelled "filtered". See text for details.

are primarily due to the PEARL-FTS a priori and due to vertical features that PEARL-FTS cannot resolve.

Figure 10 also shows that applying the sPV criterion has little effect below $25 \mathrm{~km}$, and actually makes the difference slightly larger above $25 \mathrm{~km}$. Similarly (but not shown), we find that limiting collocations to half the distance and half the time interval (i.e. $250 \mathrm{~km}, 12 \mathrm{~h}$ ) results in median differences decreasing by up to $50 \%$ at an altitude of $10 \mathrm{~km}$, but increasing differences by $25-50 \%$ at $20-25 \mathrm{~km}$. This can be explained by the relatively homogenous distribution of methane in space and time.

Figure 11 shows the distribution of methane profiles for collocated measurements between PEARL-FTS and TANSO-FTS, with PEARL-FTS either smoothed or "raw"/unsmoothed. Like Fig. 9, it shows the familiar pattern of methane, roughly constant below the tropopause, and decreasing with altitude above it. The distribution is not symmetric around the median, but the 1st quartile is closer to the median than the 3rd, a pattern opposite to the PEARL-FTSACE-FTS profiles shown in Fig. 9. The smoothed PEARLFTS profile is cut off at $30 \mathrm{~km}$ because TANSO-FTS a priori profiles are available only up to $1 \mathrm{kPa}$.

Figure 12 shows the distribution of the difference TANSOFTS-PEARL-FTS. Due to the low information content in TANSO-FTS retrievals, the profiles shown in Fig. 11 do not contain any profile information, but are rather a scaled version of the a priori (see also Sect. 3.2). Therefore, the very small differences for the smoothed version shown in Fig. 12 do not mean that the two retrievals agree very well, but rather follows directly from Eq. (3): where TANSO-FTS contains almost no information (see Fig. 2), smoothed PEARL-FTS tends to be very similar to TANSO-FTS a priori and therefore to TANSO-FTS itself. Only below $15 \mathrm{~km}$, where TANSOFTS has some sensitivity, we can see a nonzero spread in the differences between smoothed PEARL-FTS and TANSOFTS, although the median of the differences is still less than 5 ppbv. The 1st quartile of the difference has values down to $-20 \mathrm{ppbv}$, whereas the $3 \mathrm{rd}$ quartile has values up to approximately $15 \mathrm{ppbv}$. Figure 12 also shows there is a large difference between the unsmoothed version of PEARL-FTS with TANSO-FTS, but this is primarily due to differences in the a priori used.

Figure 13 shows the distribution of methane profiles for collocations between smoothed ACE-FTS and TANSO-FTS, with ACE-FTS either smoothed to TANSO-FTS, or not. Median methane as a function of altitude shows a similar pattern as in the previous comparisons, and again, it is clear that methane is not symmetrically (and therefore not normally) distributed. Figure 14 shows the differences between the two data sets. The caveat described above, when discussing Figs. 11 and 12, applies equally to the ACE-FTSTANSO-FTS comparison. Therefore, the smoothed difference is essentially zero at altitudes above $15 \mathrm{~km}$. Below $15 \mathrm{~km}$, roughly three-quarters of TANSO-FTS retrievals are larger than ACE-FTS, with a median bias of around $20 \mathrm{ppbv}$ in the troposphere. Again, unsmoothed comparisons show a much larger difference because of the choice of the a priori used for TANSO-FTS (ACE-FTS retrievals are not sensitive to any a priori).

\subsection{Partial column comparisons}

Considering the low measurement information content for TANSO-FTS and to a lesser degree PEARL-FTS, we 


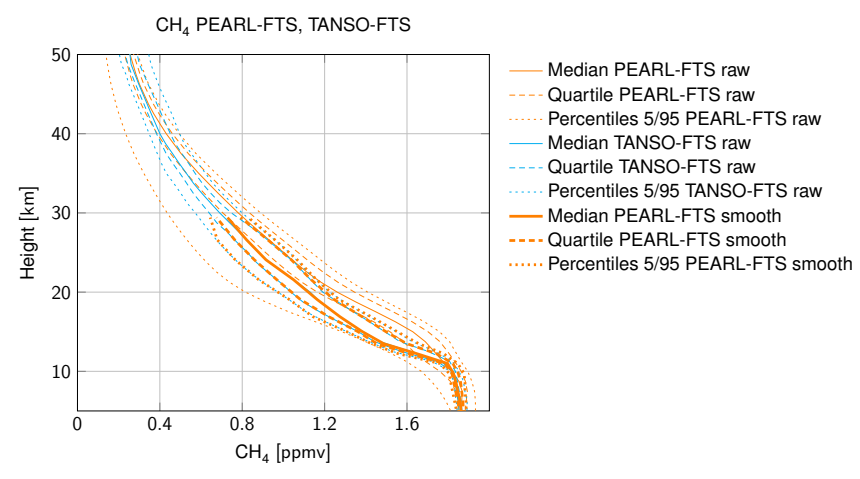

Figure 11. As in Fig. 9, but for PEARL-FTS and TANSO-FTS.

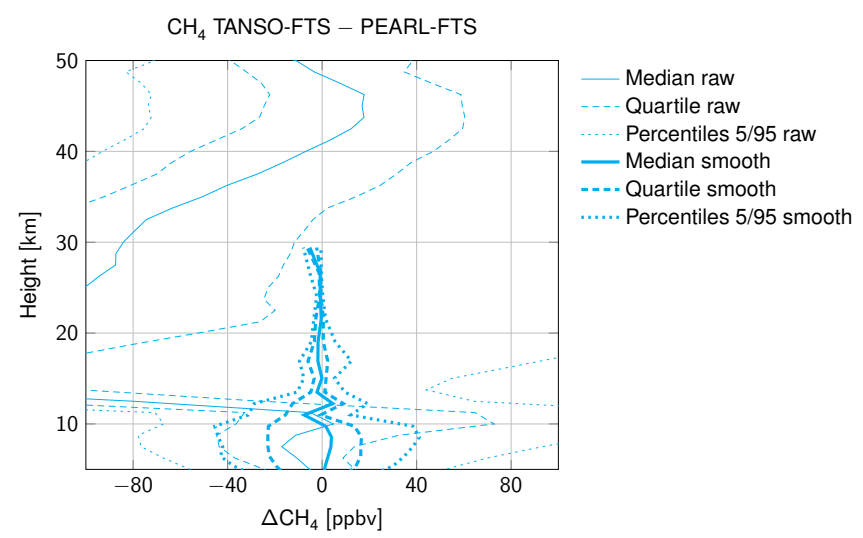

Figure 12. As in Fig. 10, but for PEARL-FTS and TANSO-FTS.

also calculate and compare partial columns as outlined in Sect. 2.7. From the analysis in Sect. 3.2, we have calculated an optimal vertical range for each pair of data sets. Table 2 shows the vertical range for each data set, as well as characteristics of the partial column differences. Here, smoothing (Sect. 2.4) and averaging (Sect. 2.6) have been applied, but polar vortex filtering has not, as the profile comparison described above showed no significant effect.

Figure 15 shows the DOFS for PEARL-FTS and TANSOFTS partial columns, when they are collocated to ACE-FTS or to each other. Each pair that involves TANSO-FTS has DOFS in the partial columns of less than 0.6 because the inclusion of TANSO-FTS necessitates a relatively small vertical range of approximately $5-10 \mathrm{~km}$. TANSO-FTS partial columns have DOFS between 0 and 0.4 in collocations with either PEARL-FTS or ACE-FTS. PEARL-FTS partial column information content is less than 0.6 when collocated with TANSO-FTS (partial column range 5.3-9.7 km), but in the range of 1.1-2.1 when collocated with ACE-FTS (partial column range $5.3-29.9 \mathrm{~km}$ ), with a mode of 1.7 DOFS.

Figure 16 shows partial column differences between PEARL-FTS and smoothed ACE-FTS for altitudes in a range of $5.3-29.9 \mathrm{~km}$, with the lower limit determined by ACEFTS and the upper limit by PEARL-FTS, based on the

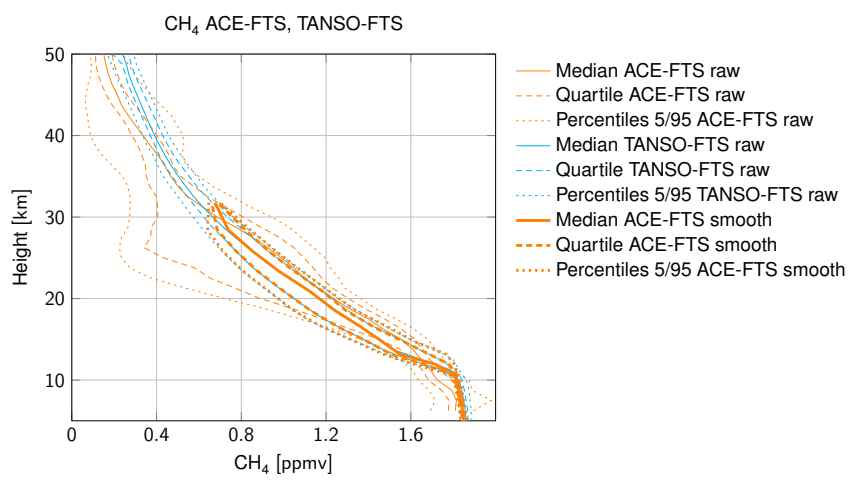

Figure 13. As in Fig. 9, but for ACE-FTS and TANSO-FTS. Note that collocations are limited to the quadrangle $60-90^{\circ} \mathrm{N}, 120$ $40^{\circ} \mathrm{W}$.

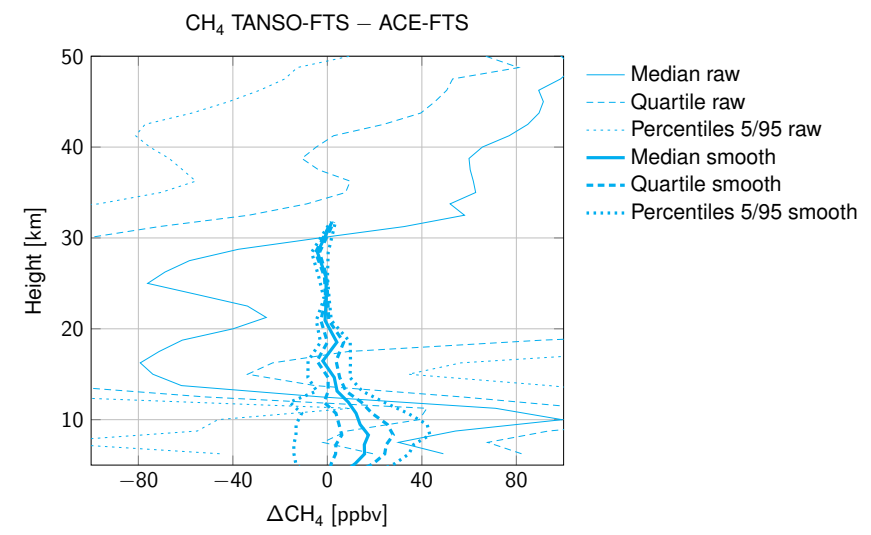

Figure 14. As in Fig. 10, but for ACE-FTS and TANSO-FTS. Note that collocations are limited to the quadrangle $60-90^{\circ} \mathrm{N}, 120$ $40^{\circ} \mathrm{W}$.

method described in Sect. 3.2. We choose to show $\Delta \mathrm{CH}_{4}$ vs. PEARL-FTS $\mathrm{CH}_{4}$ rather than ACE vs. PEARL, so that the difference and its dependences are apparent. Horizontal error bars show uncertainties calculated from random uncertainty in PEARL-FTS, propagated to partial columns with an equation similar to Eq. (9), but using SPEARL-FTS. Vertical error bars show $\sigma_{\mathrm{tot}}=\sigma_{\mathrm{PC}}+\sigma_{p T}$, where the components on the right hand side are described in Eqs. (9) and (5), respectively. Systematic errors are not considered in this error calculation. Note that data shown here are not filtered by sPV values, since we did not find that this improved the comparison (see above). The figure shows that for most collocation pairs, there is a significant difference between the two retrievals. All differences lie within a range of $\pm 3 \times 10^{22}$ molecules $\mathrm{cm}^{-2}$ for a range of PEARL-FTS partial columns between $1.3 \times 10^{23}$ and $1.9 \times 10^{23}$ molecules $\mathrm{cm}^{-2}$. The median difference ACEFTS-PEARL-FTS is $-2.6 \times 10^{21}$ molecules $\mathrm{cm}^{-2}$, which corresponds to $1.6 \%$ of the median PEARL-FTS partial column of $1.64 \times 10^{23}$ molecules $\mathrm{cm}^{-2}$. The median absolute deviation (MAD) is $2.6 \times 10^{21}$ molecules $\mathrm{cm}^{-2}$. The linear re- 
Table 2. Summary of partial column differences. The upper two rows show the range over which partial columns are calculated, based on an optimization of the information content as described in Sect. 3.2. The median $\Delta$ shows the median of secondary - primary. MAD is median absolute deviation. Unless indicated otherwise, all units are in molecules $\mathrm{cm}^{-2}$.

\begin{tabular}{lccc}
\hline $\begin{array}{l}\text { Primary } \\
\text { Secondary }\end{array}$ & $\begin{array}{c}\text { PEARL-FTS } \\
\text { ACE-FTS }\end{array}$ & $\begin{array}{c}\text { PEARL-FTS } \\
\text { TANSO-FTS }\end{array}$ & $\begin{array}{c}\text { ACE-FTS } \\
\text { TANSO-FTS }\end{array}$ \\
\hline Lower altitude $(\mathrm{km})$ & 5.3 & 5.3 & 5.2 \\
Upper altitude (km) & 29.9 & 9.7 & 9.5 \\
Median par. col., prim. & $164 \times 10^{21}$ & $942 \times 10^{20}$ & $945 \times 10^{20}$ \\
Median par. col., sec. & $161 \times 10^{21}$ & $942 \times 10^{20}$ & $940 \times 10^{20}$ \\
Median $\Delta$ (sec.-prim.) & $-2.6 \times 10^{21}$ & $0.11 \times 10^{20}$ & $7.4 \times 10^{20}$ \\
MAD & $2.6 \times 10^{21}$ & $9.6 \times 10^{20}$ & $6.0 \times 10^{20}$ \\
Median $\Delta$ (\%) & -1.6 & 0.012 & 0.78 \\
MAD (\%) & 1.6 & 1.0 & 0.64 \\
Offset/intercept & $72.3 \pm 4.1 \times 10^{21}$ & $467 \pm 16 \times 10^{20}$ & $217 \pm 39 \times 10^{20}$ \\
Slope (no unit) & $-0.456 \pm 0.025$ & $-0.497 \pm 0.017$ & $-0.224 \pm 0.041$ \\
\hline
\end{tabular}

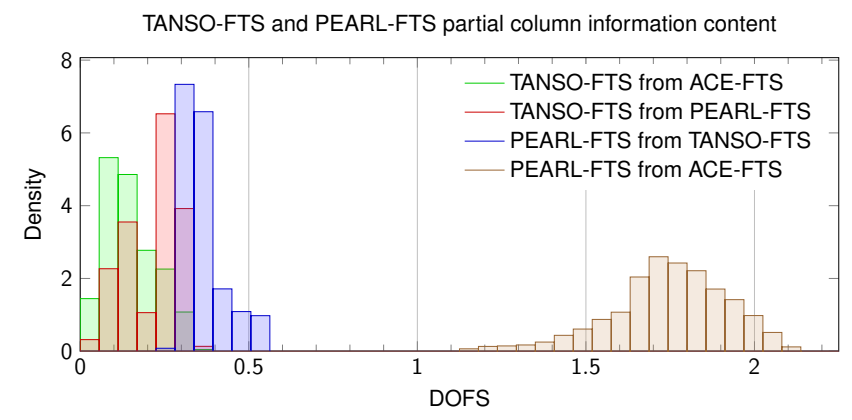

Figure 15. Information content (DOFS) for partial columns. Each histogram shows DOFS for a data set collocated with another data set; for example, one of the PEARL-FTS histograms shows DOFS for PEARL-FTS partial columns collocated with TANSOFTS, whereas the other PEARL-FTS histogram shows DOFS for PEARL-FTS partial columns collocated with ACE-FTS. The histograms are normalized such that the total area for each histogram equals 1 .

gression has a slope of $-0.456 \pm 0.25$ and an intercept of $7.23 \pm 0.41 \times 10^{22}$ molecules $\mathrm{cm}^{-2}$.

Figure 17 shows partial column differences between smoothed PEARL-FTS and TANSO-FTS for altitudes between 5.3 and $9.7 \mathrm{~km}$, with the range determined from TANSO-FTS as described in Sect. 3.2. Error bars are calculated analogously to the case of PEARL-FTS and ACE-FTS described above. In the figure, the bulk of collocated measurements are clustered around PEARL-FTS partial column values in the range of $0.89-0.97 \times 10^{23}$ molecules $\mathrm{cm}^{-2}$ with a much smaller number of larger values. For measurements where PEARL-FTS reports a higher methane partial column, the difference between TANSO-FTS and PEARL-FTS increases; indeed, the linear regression has a slope of $-0.497 \pm$ 0.17 and an intercept of $4.67 \pm 0.16 \times 10^{22}$ molecules $\mathrm{cm}^{-2}$. If TANSO-FTS and PEARL-FTS reported identical partial column retrievals, the slope of this regression would be 0 .
However, if TANSO-FTS retrievals had no dependency on methane at all, the slope would likely be close to -1 . The observation that the regression slope lies between -1 and 0 shows that TANSO-FTS methane retrievals have some sensitivity to the actual methane column. This is consistent with the TANSO-FTS DOFS lying between 0 and 1 . The median difference is $1.1 \times 10^{19}$ molecules $\mathrm{cm}^{-2}$ with a MAD of $9.6 \times 10^{20}$ molecules $\mathrm{cm}^{-2}$. A second regression line shows the same regression excluding any data points deviating from the PEARL-FTS median by more than 5 times its MAD (there are 27 points deviating more than 3 times the MAD, 4 points deviating more than 5 times, and 1 point deviating more than 10 times). This reduces the slope somewhat, but there is still considerable overlap between the confidence bands throughout the range of PEARL-FTS values (including suspected outliers).

Figure 18 shows partial column differences between TANSO-FTS and ACE-FTS for altitudes between 5.2 and $9.5 \mathrm{~km}$. The figure shows ACE-FTS measurements between $0.87 \times 10^{23}$ and $0.99 \times 10^{23}$ molecules $\mathrm{cm}^{-2}$, with TANSOFTS differences similar to the upper left cluster shown in Fig. 17. Based on the small range of values, it is hard to draw firm conclusions about differences between TANSO-FTS and ACE-FTS. Here, the linear regression has a slope of $-0.224 \pm 0.41$ and an intercept of $2.17 \pm 0.39 \times$ $10^{22}$ molecules $\mathrm{cm}^{-2}$. The slope is about half as large as the regression slope for the other two comparisons. The median difference is $7.4 \times 10^{20}$ molecules $\mathrm{cm}^{-2}$ with a MAD of $6.0 \times 10^{20}$ molecules $\mathrm{cm}^{-2}$.

\section{Discussion}

Above, we have presented a cross-validation between PEARL-FTS, ACE-FTS, and TANSO-FTS. Information content, bias, and random errors, have implications for users. PEARL-FTS retrievals tend to have DOFS between 1.5 and 3 (Fig. 3), which means there is some vertical information in 


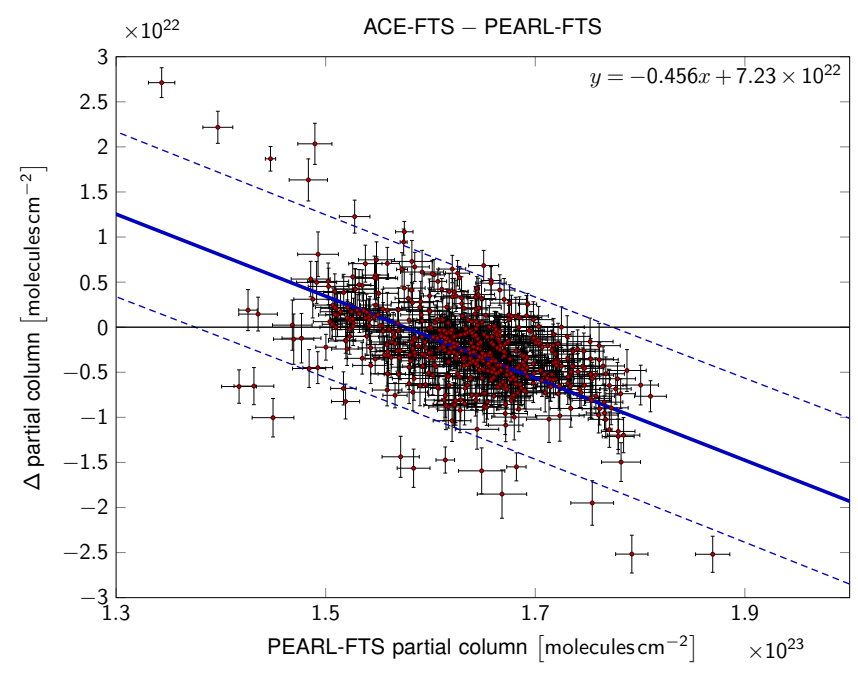

Figure 16. Partial column differences ACE-FTS - PEARL-FTS as a function of PEARL-FTS partial column. Based on a shared sensitivity calculations, partial columns are estimated in a range of 5.3$29.9 \mathrm{~km}$. The solid blue line shows the results of a linear model with the parameters for offset and slope obtained with a weighted least squares fit. The dashed blue lines show a $95 \%$ confidence interval around this estimate. The equation in the upper right describes the linear model fit. See Table 2 for uncertainty estimates on slope and offset.

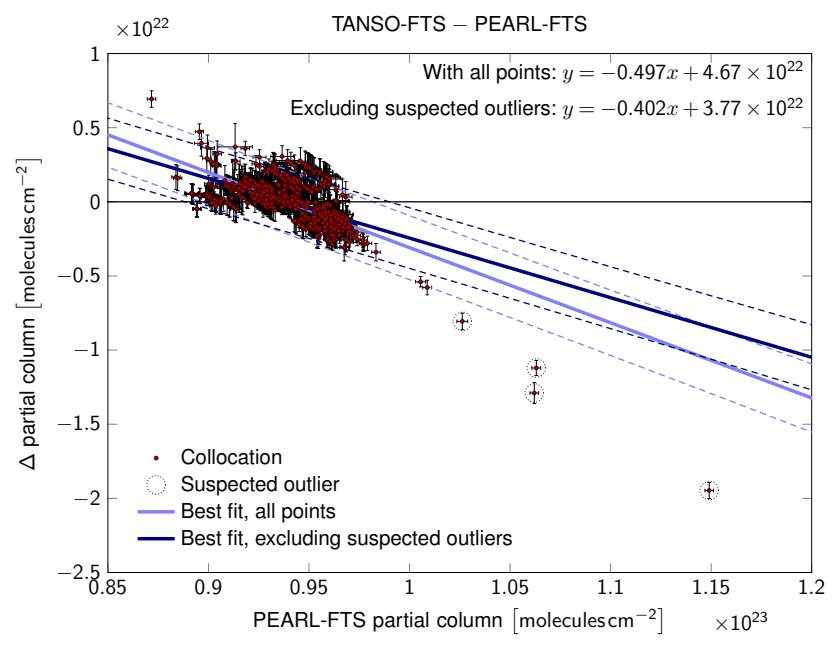

Figure 17. As in Fig. 16, but showing TANSO-FTS - PEARL-FTS in the range of $5.3-9.7 \mathrm{~km}$. The two regression lines correspond to a regression with either all points (light blue), or with suspected outliers excluded from the linear regression (dark blue) as described in the text.

the measurement. PEARL-FTS retrieves systematically more methane than smoothed ACE-FTS as shown by Figs. 10, 16, and Table 2. For partial columns in the range of 5.3-29.9 km (with DOFS still typically in a range of 1.1-2.2 as shown in Fig. 15), the median difference ACE-FTS-PEARL-FTS is $-2.6 \pm 2.6 \times 10^{21}$ molecules $\mathrm{cm}^{-2}$, or $-1.6 \pm 1.6 \%$. Those

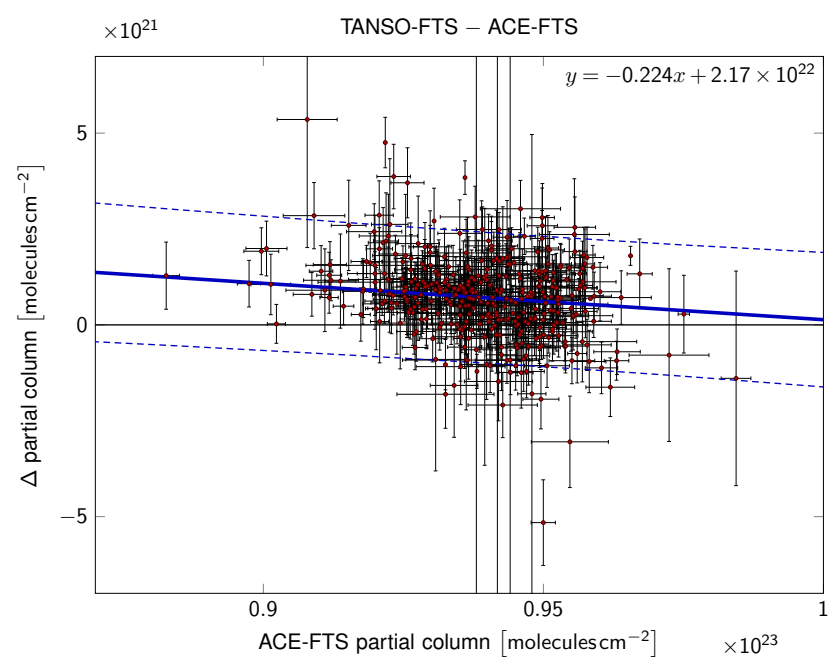

Figure 18. As in Fig. 16, but showing TANSO-FTS - ACE-FTS in a range of $5.2-9.5 \mathrm{~km}$.

differences are robust when only a subset of the data are considered, as the selection based on SPV values in Fig. 10 shows. For comparison, De Mazière et al. (2008) find that ACE-FTS V2.2 profiles have a difference of $0.3 \pm 1.5 \% \mathrm{com}-$ pared to Thule (high Arctic), $3.0 \pm 1.6 \%$ compared to Kiruna (near the Arctic circle), and 9.8 $\pm 3.5 \%$ compared to Poker Flat (sub-Arctic). Thus, our ACE-FTS V3.5-PEARL-FTS comparison is compatible with comparisons at the only other Arctic site, Thule, but inconsistent compared to earlier comparisons with Kiruna and Poker Flat, which exist in different climatic zones. However, as De Mazière et al. (2008) use V2.2 and we use V3.5, results are not directly comparable.

The very low information content for TANSO-FTS retrievals (Figs. 3 and 4) shows that these do not contain vertically resolved information. Information content for partial columns calculated near peak sensitivity is less than the information content for complete profiles (Fig. 15). However, even when DOFS are between $0.1-0.4$, there is at least some information in the retrieval due to the measurement. This can be independently confirmed by considering the partial column differences between TANSO-FTS and PEARL-FTS. The linear regression for TANSO-FTSPEARL-FTS, shown in Fig. 17, has an estimated slope of $-0.497 \pm 0.17$, i.e. significantly negative. This confirms that TANSO-FTS and PEARL-FTS retrievals are both sensitive to what is reported as methane. Due to the low TANSOFTS information content, smoothed PEARL-FTS is necessarily very close to TANSO-FTS. Indeed, as shown by Table 2, the bias of methane partial columns from TANSOFTS compared to PEARL-FTS is essentially $0(1.10 \pm 9.60 \times$ $10^{19}$ molecules $\mathrm{cm}^{-2}$ ), but this says more about the smoothing than about the reliability of TANSO-FTS.

The very low information content we find for TANSOFTS is consistent with Herbin et al. (2013), who consider 
using the different TANSO-FTS bands to retrieve $\mathrm{CO}_{2}$ and methane from one or more bands simultaneously, over either ocean or a desert surface. They find that above a desert surface, methane retrievals using only the TIR band (that we use here) have 0.84 DOFS, with information content over sea water much lower (they report 0.51 DOFS when combining TIR with shortwave bands, but do not report results for TIR-only retrievals over sea water). Considering that in our study we focus on the more difficult case of mixed surfaces in the high Arctic, it is consistent that the DOFS for our retrievals are more often than not below 0.5 .

Errors in methane retrievals - whether accounted for or not - originate from different sources, but are dominated by spectroscopy. For example, for the PEARL-FTS methane profiles, the average error due to spectroscopy overall is $7.88 \%$, including an error due to line intensities of $7.52 \%$. For comparison, the next largest contributing error is due to the solar zenith angle, and is $0.55 \%$. Moreover, the Voigt line shape as used by many retrievals does not take into account line mixing effects (for methane), even though those are relevant (Mondelain et al., 2007). More generally, spectroscopic transitions for the methane molecule are difficult to accurately measure in a laboratory or calculate from physicsbased models (Brown et al., 2013). Therefore, spectroscopic differences alone may account for a large part of both random and systematic differences between different retrievals.

Other error sources are likely not significant. Clear sky bias should not be an issue for methane retrievals, and even if it were, it affects all three data sets equally, so it cannot have an effect on a cross-validation. The same applies for the observation that collocations only occur at particular times and locations. Different estimates in temperature and pressure do affect the retrieval, but we have already quantified those, and those are not enough to explain the difference.

\section{Conclusions}

We have presented an analysis of the differences between methane retrievals obtained from PEARL-FTS, ACE-FTS, and TANSO-FTS. We have shown that measurement information content varies considerably between the three data sets, and that care needs to be taken when interpreting retrievals from PEARL-FTS and TANSO-FTS as profiles. In particular for retrievals from the TANSO-FTS TIR band, the measurement information content is too low for a true profile retrieval because of the low thermal contrast and the low signal-to-noise ratio of the $\mathrm{CH}_{4}$ retrieval band of TANSOFTS.

Although the measurement information content for TANSO-FTS is very low and information content for partial columns collocated with PEARL-FTS or ACE-FTS is even lower, this information content is non-zero, as confirmed by the slope between the partial column difference TANSO-FTS-PEARL-FTS and PEARL-FTS partial columns. Therefore, the measurement is not without value. A future study should more specifically address detectability: for example, if there is a significant but spatially concentrated methane emission somewhere in the Arctic or subArctic, will TANSO-FTS TIR be able to detect this? This question could be addressed using known emission events or simulated data. Future work is also needed to extend the comparisons to be global.

Uncertainties in retrievals arise from a variety of sources. Ideally, full metrological traceability should be applied in any satellite validation exercise (Verhoelst et al., 2015). This should also include sensitivity of the retrieval to differences in spectroscopic data, such as differences between HITRAN 2004 (used for TANSO-FTS and ACE-FTS) or 2008 (used for PEARL-FTS). Additional work is needed to assess the impact of these differences.

Another important aspect not considered in this study is stability. Collocations between PEARL-FTS and ACE-FTS cover a period of at least 8 years and counting, which may be long enough to investigate if systematic or random errors vary over time.

A more theoretical question to address is what would be needed to get a better estimate of methane than we have? As shown, TANSO-FTS TIR retrievals have very low information content in the Arctic. What would be needed - in terms of measurement or knowledge of forward model parameters - to improve this? Kulawik et al. (2013) provide an overview of studies estimating what $\mathrm{CO}_{2}$ precisions are needed - similar studies should be done for methane. This is relevant not only for pure research, but also for policy, as summarized by Ciais et al. (2014). Overall, more work is needed to address the use of thermal infrared satellite measurements for Arctic methane retrievals. 


\section{Appendix A: Derivation of covariance approximation}

To approximate $\mathbf{S}_{\text {lin }}$ from $\mathbf{S}_{\mathrm{log}}$, we use the Taylor expansion,

$$
\begin{aligned}
& E[f(X)] \approx \\
& E\left[f\left(\mu_{x}\right)+f^{\prime}\left(\mu_{x}\right)\left(X-\mu_{x}\right)+\frac{1}{2}\left(f^{\prime \prime}\left(\mu_{x}\right)\left(X-\mu_{x}\right)^{2}\right)\right] \\
& \quad=f\left(\mu_{x}\right)+\frac{f^{\prime \prime}\left(\mu_{x}\right)}{2} \sigma_{x}^{2},
\end{aligned}
$$

where $E[X]$ is the expectation value of $X, \mu_{X}$ is the mean of $X$, and $\sigma_{X}^{2}$ is the variance of $X$. The last step follows from $E\left[X-\mu_{X}\right]=0$ and $E\left[\left(X-\mu_{X}\right)^{2}\right] \equiv \sigma_{X}^{2}$. Using the definition of the covariance,

$$
\begin{aligned}
\operatorname{Cov}(X, Y) & \equiv E[(X-E[X])(Y-E[Y])]=E[X Y] \\
& -E[X] E[Y],
\end{aligned}
$$

and substituting $U=\log (X), V=\log (Y)$, and $W=U+V$, we have

$$
\begin{aligned}
E(X Y) & =E\left(e^{U} e^{V}\right)=E\left(e^{W}\right) \approx \exp \left(\mu_{W}\right)+\exp \left(\mu_{W}\right) \frac{\sigma_{W}^{2}}{2} \\
& \approx \exp \left(\mu_{W}+\frac{\sigma_{W}^{2}}{2}\right),
\end{aligned}
$$

where the last step follows from the Taylor approximation $\exp (a) \approx 1+a$, taking $a=\frac{\sigma_{W}^{2}}{2}: \exp \left(\mu_{W}\right)\left(1+\frac{\sigma_{W}^{2}}{2}\right) \approx$ $\exp (\mu) \exp \left(\frac{\sigma_{m} u^{2}}{2}\right)=\exp \left(\mu_{W}+\frac{\sigma_{W}^{2}}{2}\right)$.
Combining the above with the equivalence $\sigma_{U+V}^{2}=\sigma_{U}^{2}+$ $\sigma_{V}^{2}+2 \operatorname{Cov}(U, V)$, we have

$$
\begin{aligned}
& 1+\frac{\operatorname{Cov}(X, Y)}{E(X) E(Y)}=\frac{E(X Y)}{E(X) E(Y)} \\
& \approx \frac{\exp \left(\mu_{W}+\frac{\sigma_{W}^{2}}{2}\right)}{\exp \left(\mu_{U}+\frac{\sigma_{U}^{2}}{2}\right) \exp \left(\mu_{V}+\frac{\sigma_{V}^{2}}{2}\right)} \\
& =\frac{\exp \left(\mu_{U}+\mu_{V}+\frac{1}{2}\left(\sigma_{U}^{2}+\sigma_{V}^{2}+2 \operatorname{Cov}(U, V)\right)\right)}{\exp \left(\mu_{U}+\frac{\sigma_{U}^{2}}{2}\right) \exp \left(\mu_{V}+\frac{\sigma_{V}^{2}}{2}\right)} \\
& =\exp (\operatorname{Cov}(U, V)),
\end{aligned}
$$

from which, by rearranging, we get

$\operatorname{Cov}(\log (X), \log (Y))=E(X) E(Y) \exp (\operatorname{Cov}(X, Y)-1)$. 
Acknowledgements. This work is supported by a grant from Natural Sciences and Engineering Research Council (NSERC) under the Climate Change and Atmospheric Research (CCAR) Initiative Probing the Atmosphere of the High Arctic (PAHA) (grant number RGPCC-433842-2012).

Access to GOSAT data is supported by Japan Aerospace eXploration Agency (JAXA), NIES, and the Ministry Of the Environment (MOE) of Japan.

SCISAT/ACE is funded primarily by the Canadian Space Agency (CSA).

We thank Gloria L. Manney (Northwest Research Associates) and William H. Daffer (Jet Propulsion Laboratory) for calculating and providing the derived meteorological products for ACE-FTS and the PEARL FTIR used in this project.

The PEARL is operated by the CAnadian Network for the Detection of Atmospheric Change (CANDAC), and funded by Aboriginal Affairs and Northern Development Canada (AANDC), the Arctic Research Infrastructure Fund (ARIF), the Atlantic Innovation Fund (AIF)/Nova Scotia Research and Innovation Trust (NSRIT), the Canadian Foundation for Climate and Atmospheric Sciences (CFCAS), the Canada Foundation for Innovation (CFI), CSA, Environment Canada (EC), the Government Of Canada (GOC)International Polar Year (IPY), NSERC, the Ontario Innovation Trust (OIT), the Ontario Research Fund (ORF), and the Polar Continental Shelf Program (PCSP).

Logistical and operational support at Eureka is supported by PEARL Site Manager Pierre Fogal, CANDAC operators, and the EC Weather Station.

ACE/Optical Spectrograph and InfraRed Imager System (OSIRIS) Arctic Validation Campaigns are supported primarily by CSA with additional funding from EC, NSERC, and the Northern Scientific Training Program (NSTP).

Edited by: H. Worden

\section{References}

Amante, C. and Eakins, B.: ETOPO1 1 arc-minute global relief model: procedures, data sources and analysis, Tech. rep., NOAA NESDIS NGDC, Boulder, CO, USA, 2009.

Batchelor, R. L., Strong, K., Lindenmaier, R., Mittermeier, R. L., Fast, H., Drummond, J. R., and Fogal, P. F.: A new Bruker IFS 125HR FTIR Spectrometer for the polar environment atmospheric research laboratory at Eureka, Nunavut, Canada: measurements and comparison with the existing Bomem DA8 spectrometer, J. Atmos. Ocean. Tech., 26, 1328-1340, doi:10.1175/2009JTECHA1215.1, 2009.

Bernath, P. F., McElroy, C. T., Abrams, M. C., Boone, C. D., Butler, M., Camy-Peyret, C., Carleer, M., Clerbaux, C., Coheur, P.F., Colin, R., DeCola, P., DeMaziére, M., Drummond, J. R., Dufour, D., Evans, W. F. J., Fast, H., Fussen, D., McConnell, J. C., McHugh, M., McLeod, S. D., Michaud, R., Midwinter, C., Nassar, R., Nichitiu, F., Nowlan, C., Rinsland, C. P., Rochon, Y. J., Rowlands, N., Semeniuk, K., Simon, P., Skelton, R., Sloan, J. J., Soucy, M.-A., Strong, K., Tremblay, P., Turnbull, D., Walker, K. A., Walkty, I., Wardle, D. A., Wehrle, V., Zander, R., and Zou, J.: Atmospheric chemistry experiment (ACE): mission overview, Geophys. Res. Lett., 32, L15S01, doi:10.1029/2005GL022386, 2005.
Boone, C. D., Nassar, R., Walker, K. A., Rochon, Y., McLeod, S. D., Rinsland, C. P., and Bernath, P. F.: Retrievals for the Atmospheric Chemistry Experiment Fourier-Transform Spectrometer, Appl. Optics, 44, 7218-7231, 2005.

Boone, C. D., Walker, K. A., and Bernath, P. F.: Version 3 retrievals for the Atmospheric Chemistry Experiment Fourier Transform Spectrometer (ACE-FTS), in: The Atmospheric Chemistry Experiment ACE at 10: A Solar Occultation Anthology, edited by: Bernath, P. F., A. Deepak Publishing, Hampton, Virginia, USA, 103-127, 2013.

Bréon, F.-M. and Ciais, P.: Spaceborne remote sensing of greenhouse gas concentrations, C. R. Geosci., 342, 412-424, doi:10.1016/j.crte.2009.09.012, 2010.

Brown, L. R., Sung, K., Benner, D. C., Devi, V. M., Boudon, V., Gabard, T., Wenger, C., Campargue, A., Leshchishina, O., Kassi, S., Mondelaind, D., Wang, L., Daumont, L., Régalia, L., Rey, M., Thomas, X., Tyuterev, V. G., Lyulin, O., Nikitin, A., Niederer, H., Albert, S., Bauerecker, S., Quack, M., O’Brien, J., Gordon, I., Rothman, L., Sasada, H., Coustenis, A., Smith, M., Jr., T. C., Wang, X.-G., Mantz, A., and Spickler, P.: Methane line parameters in the HITRAN2012 database, J. Quant. Spectrosc. Ra., 130, 201-219, 2013.

Calisesi, Y., Soebijanta, V. T., and van Oss, R.: Regridding of remote soundings: formulation and application to ozone profile comparison, J. Geophys. Res., 110, D23306, doi:10.1029/2005JD006122, 2005.

Ciais, P., Sabine, C., Bala, G., Bopp, L., Brovkin, V., Canadell, J., Chhabra, A., DeFries, R., Galloway, J., Heimann, M., Jones, C., Quéré, J. L., Myneni, R. B., Piao, S., and Thornton, P.: Carbon and other biochemical cycles, in: Climate Change 2013: The Physical Science Basis. Contribution of Working Group I to the Fifth Assessment Report of the Intergovernmental Panel on Climate Change, edited by: Stocker, T. F., Qin, D., Plattner, G.K., Tignor, M., Allen, S. K., Boschung, J., Nauels, A., Xia, Y., Bex, V., and Midgley, P. M., Cambridge University Press, Cambridge, UK and New York, NY, USA, 465-570, 2013.

Ciais, P., Dolman, A. J., Bombelli, A., Duren, R., Peregon, A., Rayner, P. J., Miller, C., Gobron, N., Kinderman, G., Marland, G., Gruber, N., Chevallier, F., Andres, R. J., Balsamo, G., Bopp, L., Bréon, F.-M., Broquet, G., Dargaville, R., Battin, T. J., Borges, A., Bovensmann, H., Buchwitz, M., Butler, J., Canadell, J. G., Cook, R. B., DeFries, R., Engelen, R., Gurney, K. R., Heinze, C., Heimann, M., Held, A., Henry, M., Law, B., Luyssaert, S., Miller, J., Moriyama, T., Moulin, C., Myneni, R. B., Nussli, C., Obersteiner, M., Ojima, D., Pan, Y., Paris, J.-D., Piao, S. L., Poulter, B., Plummer, S., Quegan, S., Raymond, P., Reichstein, M., Rivier, L., Sabine, C., Schimel, D., Tarasova, O., Valentini, R., Wang, R., van der Werf, G., Wickland, D., Williams, M., and Zehner, C.: Current systematic carbon-cycle observations and the need for implementing a policy-relevant carbon observing system, Biogeosciences, 11, 3547-3602, doi:10.5194/bg-113547-2014, 2014.

Clapeyron, É.: Mémoire sur la puissance motrice de la chaleur, Journal de l'École polytechnique, 23, 153-190, 1834.

De Mazière, M., Vigouroux, C., Bernath, P. F., Baron, P., Blumenstock, T., Boone, C., Brogniez, C., Catoire, V., Coffey, M., Duchatelet, P., Griffith, D., Hannigan, J., Kasai, Y., Kramer, I., Jones, N., Mahieu, E., Manney, G. L., Piccolo, C., Randall, C., Robert, C., Senten, C., Strong, K., Taylor, J., Tétard, C., Walker, 
K. A., and Wood, S.: Validation of ACE-FTS v2.2 methane profiles from the upper troposphere to the lower mesosphere, Atmos. Chem. Phys., 8, 2421-2435, doi:10.5194/acp-8-2421-2008, 2008.

Dierckx, P.: Curve and Surface Fitting with Splines, Clarendon Press, Oxford, UK, 304 pp., ISBN-10: 0198534418, 1995.

Eyring, V., Waugh, D. W., Bodeker, G. E., Cordero, E., Akiyoshi, H., Austin, J., Beagley, S. R., Boville, B. A., Braesicke, P., Brühl, C., Butchart, N., Chipperfield, M. P., Dameris, M., Deckert, R., Deushi, M., Frith, S. M., Garcia, R. R., Gettelman, A., Giorgetta, M. A., Kinnison, D. E., Mancini, E., Manzini, E., Marsh, D. R., Matthes, S., Nagashima, T., Newman, P. A., Nielsen, J. E., Pawson, S., Pitari, G., Plummer, D. A., Rozanov, E., Schraner, M., Scinocca, J. F., Semeniuk, K., Shepherd, T. G., Shibata, K., Steil, B., Stolarski, R. S., Tian, W., and Yoshiki, M.: Multimodel projections of stratospheric ozone in the 21st century, J. Geophys. Res., 112, D16303, doi:10.1029/2006JD008332, 2007.

Fogal, P. F., LeBlanc, L. M., and Drummond, J. R.: The polar environment atmospheric research laboratory (PEARL): sounding the atmosphere at $80^{\circ}$ North, Arctic, 66, 377-386, 2013.

Frankenberg, C., Meirink, J. F., Weele, M. V., Platt, U., and Wagner, T.: Assessing methane emissions from global space-borne observations, Science, 208, 1010-1014, 2005.

Herbin, H., Labonnote, L. C., and Dubuisson, P.: Multispectral information from TANSO-FTS instrument - Part 1: Application to greenhouse gases $\left(\mathrm{CO}_{2}\right.$ and $\left.\mathrm{CH}_{4}\right)$ in clear sky conditions, Atmos. Meas. Tech., 6, 3301-3311, doi:10.5194/amt-6-3301-2013, 2013.

Holl, G., Buehler, S. A., Rydberg, B., and Jiménez, C.: Collocating satellite-based radar and radiometer measurements - methodology and usage examples, Atmos. Meas. Tech., 3, 693-708, doi:10.5194/amt-3-693-2010, 2010.

Inoue, M., Morino, I., Uchino, O., Miyamoto, Y., Saeki, T., Yoshida, Y., Yokota, T., Sweeney, C., Tans, P. P., Biraud, S. C., Machida, T., Pittman, J. V., Kort, E. A., Tanaka, T., Kawakami, S., Sawa, Y., Tsuboi, K., and Matsueda, H.: Validation of $\mathrm{XCH}_{4}$ derived from SWIR spectra of GOSAT TANSO-FTS with aircraft measurement data, Atmos. Meas. Tech., 7, 2987-3005, doi:10.5194/amt-7-2987-2014, 2014.

Kulawik, S. S., Worden, J. R., Wofsy, S. C., Biraud, S. C., Nassar, R., Jones, D. B. A., Olsen, E. T., Jimenez, R., Park, S., Santoni, G. W., Daube, B. C., Pittman, J. V., Stephens, B. B., Kort, E. A., Osterman, G. B., and TES team: Comparison of improved Aura Tropospheric Emission Spectrometer $\mathrm{CO}_{2}$ with HIPPO and SGP aircraft profile measurements, Atmos. Chem. Phys., 13, 32053225, doi:10.5194/acp-13-3205-2013, 2013.

Kuze, A., Suto, H., Nakajima, M., and Hamazaki, T.: Thermal and near infrared sensor for carbon observation Fourier-transform spectrometer on the Greenhouse Gases Observing Satellite for greenhouse gases monitoring, Appl. Optics, 48, 6716-6733, 2009.

Kuze, A., Suto, H., Shiomi, K., Urabe, T., Nakajima, M., Yoshida, J., Kawashima, T., Yamamoto, Y., Kataoka, F., and Buijs, H.: Level 1 algorithms for TANSO on GOSAT: processing and on-orbit calibrations, Atmos. Meas. Tech., 5, 2447-2467, doi:10.5194/amt-5-2447-2012, 2012.

Lambert, J. H.: Anmerkungen and Zusätze zur Entwerfung der Land- und Himmerscharten, in: Beitrage zum Gebrauche der
Mathematik in deren Anwendung, Verlag von Wilhelm Engelmann, Leipzig, Germany, reprinted 1894, 3-76, 1772.

Lay, D. C.: Linear Algebra and its Applications, Pearson Education International, Boston, MA, USA, 576 pp., ISBN-10: 0201709708, 2003.

Maksyutov, S., Patra, P. K., Onishi, R., Saeki, T., and Nakazawa, T.: NIES/FRCGC global atmospheric tracer transport model: description, validation, and surface sources and sinks inversion, J. Earth Simul., 9, 3-18, 2008.

Manney, G. L., Daffer, W. H., Zawodny, J. M., Bernath, P. F., Hoppel, K. W., Walker, K. A., Knosp, B. W., Boone, C., Remsberg, E. E., Santee, M. L., Harvey, V. L., Pawson, S., Jackson, D. R., Deaver, L., McElroy, C. T., McLinden, C. A., Drummond, J. R., Pumphrey, H. C., Lambert, A., Schwartz, M. J., Froidevaux, L., McLeod, S., Takacs, L. L., Suarez, M. J., Trepte, C. R., Cuddy, D. C., Livesey, N. J., Harwood, R. S., and Waters, J. W.: Solar occultation satellite data and derived meteorological products: sampling issues and comparison with Aura Microwave Limb Sounder, J. Geophys. Res., 112, D24S50, doi:10.1029/2007JD008709, 2007.

Marsh, D. R., Mills, M. J., Kinnison, D. E., Lamarque, J.-F., Calvo, N., and Polvani, L. M.: Climate change from 1850 to 2005 simulated in CESM1 (WACCM), J. Climate, 26, 73727391, doi:10.1175/JCLI-D-12-00558.1, 2013.

Melton, J. R., Wania, R., Hodson, E. L., Poulter, B., Ringeval, B., Spahni, R., Bohn, T., Avis, C. A., Beerling, D. J., Chen, G., Eliseev, A. V., Denisov, S. N., Hopcroft, P. O., Lettenmaier, D. P., Riley, W. J., Singarayer, J. S., Subin, Z. M., Tian, H., Zürcher, S., Brovkin, V., van Bodegom, P. M., Kleinen, T., Yu, Z. C., and Kaplan, J. O.: Present state of global wetland extent and wetland methane modelling: conclusions from a model intercomparison project (WETCHIMP), Biogeosciences, 10, 753788, doi:10.5194/bg-10-753-2013, 2013.

Mohr, P., Taylor, B., and Newell, D.: CODATA recommended values of the fundamental physical constants: 2010, Rev. Mod. Phys., 84, 1527-1605, doi:10.1103/RevModPhys.84.1527, 2012.

Mondelain, D., Payan, S., Deng, W., Camy-Peyret, C., Hurtmans, D., and Mantz, A. W.: Measurement of the temperature dependence of line mixing and pressure broadening parameters between 296 and $90 \mathrm{~K}$ in the $\nu_{3}$ band of ${ }^{12} \mathrm{CH}_{4}$ and their influence on atmospheric methane retrievals, J. Mol. Spectrosc., 244, 130-137, doi:10.1016/j.jms.2007.05.005, 2007.

Moore, E. H.: On the reciprocal of the general algebraic matrix, B. Am. Meteorol. Soc., 26, 394-395, 1920.

Morino, I., Uchino, O., Inoue, M., Yoshida, Y., Yokota, T., Wennberg, P. O., Toon, G. C., Wunch, D., Roehl, C. M., Notholt, J., Warneke, T., Messerschmidt, J., Griffith, D. W. T., Deutscher, N. M., Sherlock, V., Connor, B., Robinson, J., Sussmann, R., and Rettinger, M.: Preliminary validation of column-averaged volume mixing ratios of carbon dioxide and methane retrieved from GOSAT short-wavelength infrared spectra, Atmos. Meas. Tech., 4, 1061-1076, doi:10.5194/amt-4-1061-2011, 2011.

Ohyama, H., Kawakami, S., Shiomi, K., Morino, I., and Uchino, O.: Atmospheric temperature and water vapor retrievals from GOSAT thermal infrared spectra and initial validation with coincident radiosonde measurements, SOLA, 9, 143-147, doi:10.2151/sola.2013-032, 2013.

Prather, M. J., Holmes, C. D., and Hsu, J.: Reactive greenhouse gas scenarios: systematic exploration of uncertainties and the 
role of atmospheric chemistry, Geophys. Res. Lett., 39, L09803, doi:10.1029/2012GL051440, 2012.

Raspollini, P., Belotti, C., Burgess, A., Carli, B., Carlotti, M., Ceccherini, S., Dinelli, B. M., Dudhia, A., Flaud, J.-M., Funke, B., Höpfner, M., López-Puertas, M., Payne, V., Piccolo, C., Remedios, J. J., Ridolfi, M., and Spang, R.: MIPAS level 2 operational analysis, Atmos. Chem. Phys., 6, 5605-5630, doi:10.5194/acp6-5605-2006, 2006.

Razavi, A., Clerbaux, C., Wespes, C., Clarisse, L., Hurtmans, D., Payan, S., Camy-Peyret, C., and Coheur, P. F.: Characterization of methane retrievals from the IASI space-borne sounder, Atmos. Chem. Phys., 9, 7889-7899, doi:10.5194/acp-9-7889-2009, 2009.

Rienecker, M., Suarez, M., Todling, R., Bacmeister, J., Takacs, L., Liu, H.-C., Gu, W., Sienkiewicz, M., Koster, R., Gelaro, R., Stajner, I., and Nielsen, J.: The GEOS-5 data assimilation system documentation of versions 5.0.1, 5.1.0, and 5.2.0, in: Technical Report Series on Global Modeling and Data Assimilation, edited by: Suarez, M. J., vol. 27, NASA, NASA/TM-2008-104606, Greenbelt, MD, USA, 1-101, 2008.

Rodgers, C. D.: Characterization and error analysis of profiles retrieved from remote sounding measurements, J. Geophys. Res., 95, 5587-5595, 1990.

Rodgers, C. D.: Inverse Methods for Atmospheric Sounding, World Scientific, Oxford, UK, 240 pp., ISBN-10: 981022740X, 2000.

Rodgers, C. D. and Connor, B. J.: Intercomparison of remote sounding instruments, J. Geophys. Res., 108, ACH 13-1-ACH 13-13, doi:10.1029/2002JD002299, 2003.

Rothman, L. S., Jacquemart, D., Barbe, A., Benner, D. C., Birk, M., Brown, L. R., Carleer, M. R., Jr., C. C., Chance, K., Coudert, L. H., Dana, V., Devi, V. M., Flaud, J.-M., Gamache, R. R., Goldman, A., Hartmann, J.-M., Jucks, K. W., Maki, A. G., Mandin, J.-Y., Massie, S. T., Orphal, J., Perrin, A., Rinsland, C. P., Smith, M. A. H., Tennyson, J., Tolchenov, R. N., Toth, R. A., Auwera, J. V., Varanasi, P., and Wagner, G.: The HITRAN 2004 molecular spectroscopic database, J. Quant. Spectrosc. Ra., 96, 139-204, doi:10.1016/j.jqsrt.2004.10.008, 2005.

Rothman, L. S., Gordon, I. E., Barbe, A., Benner, D. C., Bernath, P. F., Birk, M., Boudon, V., Brown, L. R., Campargue, A., Champion, J.-P., Chance, K., Coudert, L. H., Dana, V., Devi, V. M., Fally, S., Flaud, J.-M., Gamache, R. R., Goldman, A., Jacquemart, D., Kleiner, I., Lacome, N., Lafferty, W. J., Mandin, J.-Y., Massie, S. T., Mikhailenko, S. N., Miller, C. E., Moazzen-Ahmadi, N., Naumenko, O. V., Nikitin, A. V., Orphal, J., Perevalov, V. I., Perrin, A., Predoi-Cross, A., Rinsland, C. P., Rotger, M., Simeckova, M., Smith, M. A. H., Sung, K., Tashkun, S. A., Tennyson, J., Toth, R. A., Vandaele, A. C., and Auwera, J. V.: The HITRAN 2008 molecular spectroscopic database, J. Quant. Spectrosc. Ra., 110, 533-572, doi:10.1016/j.jqsrt.2009.02.013, 2009.

Saeki, T., Saito, R., Belikov, D., and Maksyutov, S.: Global highresolution simulations of $\mathrm{CO}_{2}$ and $\mathrm{CH}_{4}$ using a NIES transport model to produce a priori concentrations for use in satellite data retrievals, Geosci. Model Dev., 6, 81-100, doi:10.5194/gmd-681-2013, 2013.

Saitoh, N., Imasu, R., Ota, Y., and Niwa, Y.: $\mathrm{CO}_{2}$ retrieval algorithm for the thermal infrared spectra of the Greenhouse Gases Observing Satellite: potential of retrieving $\mathrm{CO}_{2}$ vertical profile from high-resolution FTS sensor, J. Geophys. Res., 114, D17305, doi:10.1029/2008JD011500, 2009.

Saitoh, N., Tuonu, M., Hayashida, S., Imasu, R., Shiomi, K., Yokota, T., Yoshida, Y., Machida, T., Matsueda, H., and Sawa, Y.: Comparisons between $\mathrm{XCH} 4$ from GOSAT shortwave and thermal infrared spectra and aircraft $\mathrm{CH}_{4}$ measurements over Guam, Sci. Onl. Let. Atm., 8, 145-149, 2012.

Schoeberl, M. R., Lait, L. R., Newman, P. A., and Rosenfield, J. E.: The structure of the polar vortex, J. Geophys. Res., 97, 78597882, doi:10.1029/91JD02168, 1992.

Sheese, P. E., Boone, C. D., and Walker, K. A.: Detecting physically unrealistic outliers in ACE-FTS atmospheric measurements, Atmos. Meas. Tech., 8, 741-750, doi:10.5194/amt-8-7412015, 2015.

Sussmann, R., Forster, F., Rettinger, M., and Jones, N.: Strategy for high-accuracy-and-precision retrieval of atmospheric methane from the mid-infrared FTIR network, Atmos. Meas. Tech., 4, 1943-1964, doi:10.5194/amt-4-1943-2011, 2011.

Thies, B. and Bendix, J.: Satellite based remote sensing of weather and climate: recent achievements and future perspectives, Meteorol. Appl., 18, 262-295, doi:10.1002/met.288, 2011.

Verhoelst, T., Granville, J., Hendrick, F., Köhler, U., Lerot, C., Pommereau, J.-P., Redondas, A., Van Roozendael, M., and Lambert, J.-C.: Metrology of ground-based satellite validation: co-location mismatch and smoothing issues of total ozone comparisons, Atmos. Meas. Tech., 8, 5039-5062, doi:10.5194/amt-8-5039-2015, 2015.

Vigouroux, C., De Mazière, M., Errera, Q., Chabrillat, S., Mahieu, E., Duchatelet, P., Wood, S., Smale, D., Mikuteit, S., Blumenstock, T., Hase, F., and Jones, N.: Comparisons between groundbased FTIR and MIPAS $\mathrm{N}_{2} \mathrm{O}$ and $\mathrm{HNO}_{3}$ profiles before and after assimilation in BASCOE, Atmos. Chem. Phys., 7, 377-396, doi:10.5194/acp-7-377-2007, 2007.

von Clarmann, T.: Validation of remotely sensed profiles of atmospheric state variables: strategies and terminology, Atmos. Chem. Phys., 6, 4311-4320, doi:10.5194/acp-6-4311-2006, 2006.

von Clarmann, T.: Validation of remotely sensed profiles of atmospheric state variables: strategies and terminology, Atmos. Chem. Phys., 6, 4311-4320, doi:10.5194/acp-6-4311-2006, 2006.

Waymark, C., Walker, K., Boone, C., and Bernath, P.: ACE-FTS version 3.0 data set: validation and data processing update, Ann. Geophys.-Italy, 56, doi:10.4401/ag-6339, 2013.

Wecht, K. J., Jacob, D. J., Wofsy, S. C., Kort, E. A., Worden, J. R., Kulawik, S. S., Henze, D. K., Kopacz, M., and Payne, V. H.: Validation of TES methane with HIPPO aircraft observations: implications for inverse modeling of methane sources, Atmos. Chem. Phys., 12, 1823-1832, doi:10.5194/acp-12-1823-2012, 2012.

Worden, J., Kulawik, S., Frankenberg, C., Payne, V., Bowman, K., Cady-Peirara, K., Wecht, K., Lee, J.-E., and Noone, D.: Profiles of $\mathrm{CH}_{4}, \mathrm{HDO}, \mathrm{H}_{2} \mathrm{O}$, and $\mathrm{N}_{2} \mathrm{O}$ with improved lower tropospheric vertical resolution from Aura TES radiances, Atmos. Meas. Tech., 5, 397-411, doi:10.5194/amt-5-397-2012, 2012.

Xiong, X., Barnet, C., Maddy, E., Sweeney, C., Liu, X., Zhou, L., and Goldberg, M.: Characterization and validation of methane products from the Atmospheric Infrared Sounder (AIRS), J. Geophys. Res., 113, G00A01, doi:10.1029/2007JG000500, 2008. 
Yoshida, Y., Ota, Y., Eguchi, N., Kikuchi, N., Nobuta, K., Tran, H., Morino, I., and Yokota, T.: Retrieval algorithm for $\mathrm{CO}_{2}$ and $\mathrm{CH}_{4}$ column abundances from short-wavelength infrared spectral observations by the Greenhouse gases observing satellite, Atmos. Meas. Tech., 4, 717-734, doi:10.5194/amt-4-717-2011, 2011. 